\title{
Titanium-vanadium oxide nanocomposite based solid-state dual-electrode sensor for SARS-CoV-2 nucleic acid detection
}

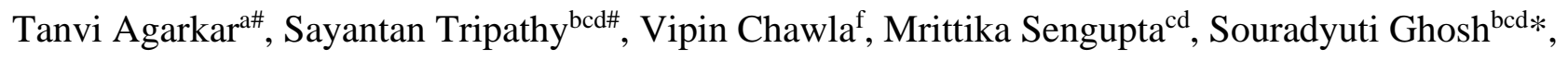
Ashvani Kumar ae**

a, Department of Physics, Bennett University, India

b, Department of Chemistry, Bennett University, India

${ }^{\mathrm{c}}$, Department of Biotechnology, Bennett University, India

${ }^{\mathrm{d}}$, Center of Excellence for Nanosensors and Nanomedicine, Bennett University, India

e, Pristine Diamonds, Vatva, India

f, Institute Instrumentation Centre, Indian Institute of Technology Roorkee, India

*, Corresponding author.

**, Corresponding author (will handle communication): ashuiit19@gmail.com.

\#, Joint first authors 


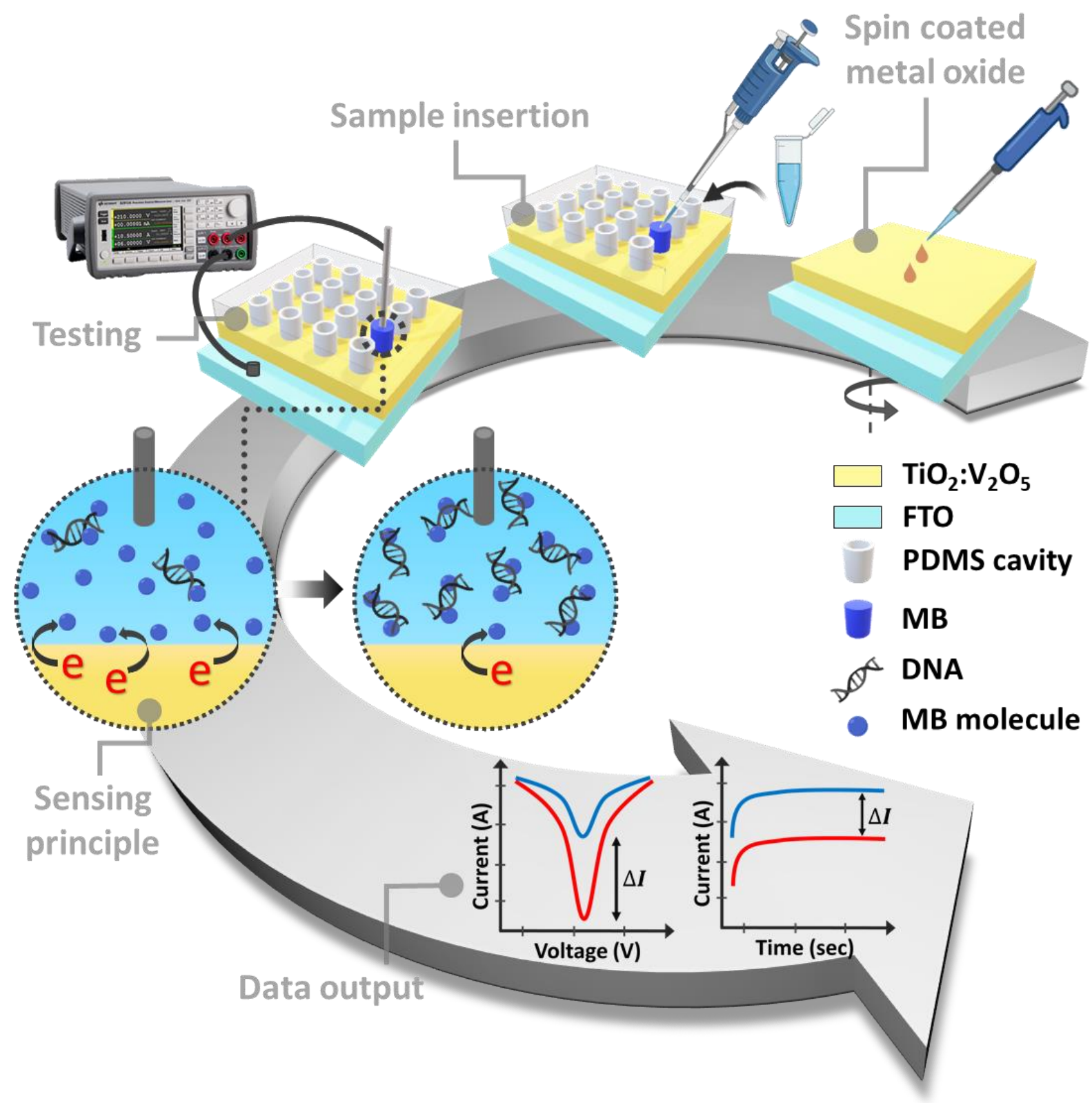




\section{Abstract:}

COVID-19 outbreak, caused by the SARS-CoV-2 RNA virus, elevates the need for a rapid, reliable, inexpensive, and easily accessible disease diagnostic tool. The present go-to approach for SARS$\mathrm{CoV}-2$ RNA detection is the real-time reverse transcriptase polymerase chain reaction (RT-PCR) test which despite being the most reliable method has few drawbacks including being lengthy and laborious. Approaching the diagnosis from an electrochemistry pathway is a relatively economical, decentralized and yet highly sensitive route. This work aims to construct an electrochemical (bio)sensor with 2-electrode geometry with a transition metal oxide (TMO) based sensing layer. We have fabricated a series of $\mathrm{TiO}_{2}-\mathrm{V}_{2} \mathrm{O}_{5}$ (TVO) nanocomposites to probe their electrochemical performance and attain a highly sensitive dual-electrode electrochemical sensor (DEES) compared to the pristine $\mathrm{V}_{2} \mathrm{O}_{5}$. The XRD analysis of the electrodes confirmed the formation of nanocomposite while the XPS analysis correlated the formation of oxygen vacancies with improved electrical conduction measured via EIS and I-V characterization. The optimized electrode was then utilized to electrochemically detect end-point LAMP readout for $10^{1}-10^{4}$ copies of plasmid DNA and in vitro transcribed SARS-CoV-2 RdRp RNA in an aqueous solution. Additionally, the DEES was also applied to detect in situ LAMP performed on SARS-CoV-2 plasmid and RNA magneto-extracted from a) aqueous solution; b) sample spiked with excess human genomic DNA, and c) a viral transport medium (VTM)-mimic sample. The DEES results were compared with real-time fluorescence and commercially available screen-printed electrodes (SPE). Our device was able to successfully detect magneto-extracted plasmid DNA and in vitro transcribed SARS-CoV-2 RNA to the limit of detection of 2.5 copies $/ \mu \mathrm{L}$.

Keywords: SARS-CoV-2; electrochemical biosensor; nanocomposite; SWV; EIS; magnetocapture 


\section{Introduction:}

Severe acute respiratory syndrome coronavirus 2 (SARS-CoV-2) has been declared a pandemic by the WHO on $11^{\text {th }}$ March 2020, within a few months after the reported first case. ${ }^{1}$ The virus has an enormous socio-economic impact worldwide. The SARS-CoV-2 is the etiological agent of coronavirus disease (COVID-19), which has infected around 25,69,66,237 people including 51,51,643 deaths, as of 22 November 2021 (according to WHO). ${ }^{2}$ Hence, Covid-19 diagnostics have been a major priority among healthcare agencies facing challenges like assay quantity, ease in data handling, reagents cost, and process time being the key points of concern. ${ }^{1}$ Presently, real-time reverse transcription polymerase chain reaction (RT-PCR) has been employed as the gold standard of detection owing to its accuracy, and specificity ${ }^{3,4}$. However, this approach is time-intensive, demanding a specialized laboratory with high-priced instruments and trained personnel for nasopharyngeal/ oropharyngeal (NP/OP) sample collection ${ }^{4-6}$. These downsides of real-time RTPCR have spurred the advancement of various isothermal nucleic acid amplification techniques (iNAATs) such as recombinase polymerase amplification (RPA) ${ }^{7,8}$, rolling circle amplification $(\mathrm{RCA})^{4,9}$ and loop-mediated isothermal amplification (LAMP) ${ }^{10-13}$. Among these, loop-mediated isothermal amplification (LAMP) has remained the most utilized technique in terms of NCBI PubMed entries. Using 4-6 primers and a strand displacement polymerase, LAMP could generate a considerable amount of DNA concatemer amplicon within 30 - 45 min with analytical sensitivities in the order of 10 copies ${ }^{14}$. Besides optical methods such as real-time fluorescence, colourimetry, turbidimetry, surface plasmon readouts ${ }^{15-17}$, the detection of LAMP amplicons can be executed using an electrochemical biosensor (ECB) as well. In terms of NAAT molecular diagnostics in resourcelimited settings, this opens a route for rapid detection and would be a valuable asset in outbreak regions or remote zones where centralized facilities are unavailable. In terms of electrochemical detection of SARS-CoV-2, i-NAATs such as RCA as well as antigen-based techniques have been employed that detects the pathogen with a limit of detection (LOD) in the order $10-10^{3}$ copies $^{4,18}$. However, despite the advantage of LAMP and proven amenability to electrochemical NAAT, it has surprisingly not been utilized in the biosensing of SARS-CoV-2 RNA.

ECBs are beneficial for sensing a biological analyte due to their specificity, sensitivity and straightforward data interpretation ${ }^{19}$. Traditionally, an ECB is comprised of 3-electrodes, namely, working, counter, and reference electrodes. Among published reports, gold-based electrodes have 
remained the predominantly used working electrode in the electrochemical biosensing of nucleic acids ${ }^{20,21}$. Along with its very high sensitivity, gold electrode-based biosensing offer many attractive and flexible sensing options including the highly useful thiol-based surface monolayer immobilization of probe DNA ${ }^{22}$. Very recent work for the detection of SARS-CoV-2 was reported where nCovid-19 monoclonal antibody was immobilized over gold nanoparticle decorated FTO glass surface ${ }^{23}$. Although the amount of deposited gold in such electrodes was significantly low per electrode (e.g., a $3 \mathrm{~mm}$ circular gold electrode with $1 \mathrm{~mm}$ thickness would require $0.5 \mathrm{mg}$ gold), the batch processing and scaling up of the electrode preparation would require significant investment. Besides the working electrodes, the reference electrode is usually a noble metal (Pt or Ag) based electrode that also adds up to the cost of the sensor. We speculated that these could in principle increase the associated cost of electrochemical nucleic acid detection and may reduce their commercialization potential. Another common electrode of choice in biosensing assays is a commercially available screen-printed electrode (SPE) or modified SPE ${ }^{11,24-27}$. However, the SPEs also predominantly utilized either gold-based or carbon-based working electrodes. Interestingly, electrode configurations comprising of transition metal oxides (TMOs) as sensing layer are surprisingly rare in their application towards NAAT detection, and in general in biosensing. This is despite the fact that, unlike noble metals or carbon-based electrodes, TMOs offer significant versatility in terms of tuning their electrochemical properties. These properties can in principle be tuned using factors involving (but not limited to) introducing oxygen vacancies, adjusting isoelectric points, the coexistence of various oxidation states, improving electrical conductivity etc. In fact, the application of these diverse properties has been widely reported in areas such as catalysis ${ }^{28}$, fuel cell $^{29}$, supercapacitor ${ }^{30}$, and gas sensing ${ }^{31,32}$ among others. Besides the straightforward application of TMOs or SPEs as sensors, surface modification and doping induced generation of nanocomposites is another underexplored area that holds significant promise in biosensing. For instance, Lucian Rotariu et al. conclusively reported a major improvement in the nicotinamide adenine dinucleotide detection thanks to the poly(allylamine hydrochloride) (PAH) modified SPE. A research work by Hao Cai et al. reports the improved sensing performance of $\mathrm{MoO}_{3}-\mathrm{In}_{2} \mathrm{O}_{3}$ solid solution towards $\mathrm{NO}_{2}$ gas sensing as compared to pure $\operatorname{In}_{2} \mathrm{O}_{3}$, due to enhanced electrochemical activity to the cathodic reaction. ${ }^{32}$ These reports suggested that sensor functionality can be tuned by modifying the surface of the working electrode by nano-structuring ${ }^{33}$, nanocomposite ${ }^{28}$, doping $^{34}$, surface functionalization $^{6}$ etc. 
We have recently investigated the end-point detection of pathogen nucleic acid with electrochemical NAATs utilizing an oxygen-vacancy modulated $\mathrm{MnO}_{2}$ electrode in a two-electrode electrochemical device $^{35}$. Contrary to traditional three-electrode geometry, a 2-electrode device geometry with a working and pseudo- or quasi-reference counter electrode (QRCE) has the following advantages, (i) simplification of the sensor structure, (ii) lowering of the ohmic resistance effect, (iii) elimination of liquid junction potential, and (iv) avoids contamination of the target solution by the solvent molecules (or ions) of a conventional reference electrode ${ }^{36}$. By analyzing I-V characteristics and using methylene blue (MB) as the redox mediator ${ }^{35}$, the electrode successfully detected electrochemical RCA (using a pre-synthesized circular DNA as the template and a dengue virus sequence-bearing primer as target) and polymerase chain reaction (PCR, using Staphylococcus aureus vraR gene as target) with LODs in the order of $10^{3}$ copies. However, the work utilizes already purified genomic DNA or synthetic DNA as the target. It did not explore how the analytical sensitivity or selectivity of the assay would be affected in a real-life sample, potentially containing host nucleic acid or complex biofluid. In principle, a pre-concentration of analyte nucleic acid (either through electrode surface immobilization or through the utilization of magnetic beads) is expected to help improve the selectivity. However, the compatibility of such measures remains uninvestigated for two-electrode geometry devices as well as TMO based biosensors. While the work investigated the electroanalytical behavior of oxygen vacancy modulated $\mathrm{MnO}_{2}$ (isoelectric point or IEP 4-5 ${ }^{37}$ ), aspects such as surface interactions or effect of doping were not studied. These aspects, to the best of our knowledge, remain unexplored in terms of NAAT electrochemical assays or in general for electroanalytical biosensor development as well.

We hypothesized that the surface of the TMO electrode can be made negatively charged by selecting a material with lower IEP than the electrolyte solution of MB, $\mathrm{pH} 7.5$ - 8.5 (utilized in NAAT assays), to attract the positively charged methylene blue which impacts the electron transfer and enhance the assay sensitivity. Also, the fabrication of metal oxide nanocomposites can improve electronic conduction and is expected to further benefit assay performance. In addition, we also hypothesized that a magnetic pre-concentration of target nucleic acid from a real-life mimic sample (containing host nucleic acid and complex biofluid) followed by electrochemical i-NAAT (LAMP in this case) would improve assay selectivity and be compatible with these electrode modifications. In this work, these hypotheses were tested by designing a dual-electrode electrochemical sensor (DEES) with a working and QRCE electrode for end-point NAAT detection of SARS-CoV-2 nucleic acid (RdRp 
plasmid DNA and in vitro transcribed RNA). The working electrode was a fluorine-doped tin oxide (FTO) surface modified by titanium oxide- vanadium oxide $\left(\mathrm{TiO}_{2}-\mathrm{V}_{2} \mathrm{O}_{5}\right)$ binary metal oxide nanocomposite that forms the sensing layer. $\mathrm{V}_{2} \mathrm{O}_{5}$ was chosen to tune the surface charge interaction between the MB and electrode. The fabrication was done by a simple and low-cost technique called sol-gel spin coating, where $\mathrm{TiO}_{2}-\mathrm{V}_{2} \mathrm{O}_{5}$ (TVO) thin films were spin-coated on FTO from a stable mixture of vanadium and titanium oxide precursor solution. The Ti concentration in $\mathrm{V}_{2} \mathrm{O}_{5}$ was optimized in terms of the electrical and electrochemical response of the electrode. The DEES was then utilized to electrochemically detect end-point LAMP readout for SARS-CoV-2 RdRp plasmid DNA and in vitro transcribed RNA in an aqueous solution. Additionally, the sensing device was also applied to detect LAMP performed on magneto-extracted SARS-CoV-2 plasmid and RNA from a) aqueous solution; b) sample spiked with excess human genomic DNA, and c) a viral transport medium (VTM)-mimic sample. The DEES results were compared with gold-standard real-time PCR fluorescence readout and electrochemical assays performed on commercially available screenprinted electrodes (SPE).

\section{Experimental Details}

\section{Chemicals and Instrumentation}

Vanadyl (acetylacetonate) (VO(acac) $)_{2}\left(\mathrm{C}_{10} \mathrm{H}_{14} \mathrm{O}_{5} \mathrm{~V}\right)$, 1-butanol $\left(\mathrm{C}_{4} \mathrm{H}_{9} \mathrm{OH}\right)$, and benzyl alcohol $\left(\mathrm{C}_{6} \mathrm{H}_{5} \mathrm{CH}_{2} \mathrm{OH}\right)$ were procured from SRL chemical, India for the preparation of $\mathrm{V}_{2} \mathrm{O}_{5}$ precursor solution. Titanium tetraisopropoxide (TTIP) $\left(\mathrm{Ti}\left\{\mathrm{OCH}\left(\mathrm{CH}_{3}\right)_{2}\right\}_{4}\right)$, and isopropyl alcohol (IPA) were purchased from GLR Innovations and SRL chemicals, India, respectively, for the preparation of $\mathrm{TiO}_{2}$ precursor solution. Silicone Elastomer Kit, SYLGARD 184, comprised of base and curing agent was purchased from Dow Corning Corporation to prepare Polydimethylsiloxane (PDMS) polymer layer. All chemicals were analytical reagent (AR) grade and used as received without further refinement. Fluorine-doped tin oxide (FTO) deposited glass, and 99.99\% pure silver wire were procured from commercial sources and further cleaned with IPA prior to use.

The plasmid construct with RNA dependent RNA polymerase (RdRp) gene with T7 RNA polymerase promoter (4538 bp) was procured from Addgene (plasmid \#14567, https://www.addgene.org/145671/). The Bst 2.0 polymerase, RTx enzyme, dNTP, and SnaBI were purchased from NEB, USA. The SYBR I (10,000X concentrated) was purchased from Invitrogen, USA. Molecular biology grade water was purchased from HiMedia, India. The RNase inhibitor was 
purchased from Takara. Streptavidin quoted magnetic beads were purchased from Sigma or Invitrogen (Dynabeads M-280). 5'-biotinylated probe b (5'-[BIO]AAAAAAAAAACGAGCAAGAACAAGTGAGGCCATAATTC, HPLC purified) was purchased from Sigma. Primer oligonucleotides (desalting purified) were purchased from Eurofins or Sigma. The electrochemical studies such as current-voltage measurements were performed at room temperature using Keysight technologies b2901a precision source/measure unit (SMU) controlled by Quick IV Measurement software. The electrochemical impedance spectroscopy (EIS), square-wave voltammetry (SWV), and chronoamperometry (CA) were performed using Metrohm Autolab PGSTAT302N electrochemical workstation. The film thickness was evaluated using the Alpha-Step D-300 stylus profiler. The crystal structures were analyzed using Bruker D8-Advanced X-ray diffraction (XRD). Surface morphology was studied using field-emission scanning electron microscope (FESEM) Nova NanoSEM 450 (FEI). To analyze surface oxidation state X-ray photoelectron spectroscopy (XPS) was performed using Thermo Fisher NEXSA surface analyzer (supplied with Al monochromatic X-ray source, $1486.6 \mathrm{eV}$ ).

\section{Electrode fabrication:}

The $\mathrm{TiO}_{2}-\mathrm{V}_{2} \mathrm{O}_{5}$ (TVO) nanocomposite thin films were fabricated by the sol-gel spin coating technique. The $\mathrm{V}_{2} \mathrm{O}_{5}$ precursor solution was prepared by mixing 1-butanol $\left(\mathrm{C}_{4} \mathrm{H}_{9} \mathrm{OH}\right)$, and benzyl alcohol $\left(\mathrm{C}_{6} \mathrm{H}_{5} \mathrm{CH}_{2} \mathrm{OH}\right)$ solvents in the volume ratio of $1: 9$ and gradually adding $1 \mathrm{wt} \%$ of $\mathrm{VO}(\mathrm{acac})_{2}$ salt into the mixture. ${ }^{38}$ The solution was kept overnight stirring at $45^{\circ} \mathrm{C}$ with a rotation of $350 \mathrm{RPM}$. The solution colour turns a bottle green after the salt was dissolved. ${ }^{39}$ For the synthesis of $\mathrm{TiO}_{2}$ solution, liquid TTIP precursor was dissolved in IPA to achieve an equimolar solution as of $\mathrm{V}_{2} \mathrm{O}_{5}$ precursor. The TVO precursor was prepared by adding $0,10,20,30,40$, and $50 \mathrm{~mol} \%$ of $\mathrm{TiO}_{2}$ in the $\mathrm{V}_{2} \mathrm{O}_{5}$ solution.

The thin film was deposited on the conductive FTO coated glass. Before deposition, FTO was cleaned using IPA and subsequently treated with UV-Ozone to remove any surface contamination and make the surface more hydrophilic and suitable for deposition.

Spin coating was performed in two steps, initially at 1000 RPM for $30 \mathrm{sec}$ followed by 2000 RPM for $180 \mathrm{sec}$. During deposition, FTO/glass substrate was partially covered using a physical mask to make electrical contact directly on FTO. The film was then pre-annealed at $110^{\circ} \mathrm{C}$ for $10 \mathrm{~min}$. This process was repeated thrice to get the optimized film thickness. Further, the dried film was annealed 
in the air using a muffle furnace at $450^{\circ} \mathrm{C}$ for 1 hour with a heating rate of $8^{\circ} \mathrm{C} /$ minute. The films with 0, 10, 20, 30, 40, and 50 mol\% of $\mathrm{TiO}_{2}$ are addressed as 0\%-TVO, 10\%-TVO, 20\%-TVO, 30\%-TVO, 40\%-TVO, and 50\%-TVO hereafter in this manuscript, respectively.

\section{Electrode Modification and Assembly:}

Post-annealing of electrodes, electrical contacts were fabricated using newly peeled copper wire and silver conducting paste. A thin, transparent, and flexible layer of PDMS was integrated onto the electrode that functions as an electrolyte holding cavity. The cavity serves the bi-fold purpose of providing a uniform contact area for every measurement and preventing evaporation during the testing of the samples. The PDMS layer was created by mixing 10:1 ratio of SYLGARD 184 base and curing agent, respectively in a flat bottom glass plate. The PDMS was degassed using a desiccator for 5-10 minutes and cured at $70^{\circ} \mathrm{C}$ for 30 minutes. After cooling at room temperature, the moulded $2 \mathrm{~mm}$ thick PDMS was edged in a $2 \times 2.5 \mathrm{~cm}^{2}$ rectangular piece and separate circular cavities of diameter $0.25 \mathrm{~cm}$ were punched using a hole punch plier.

\section{Preparation of methylene blue solutions}

The methylene blue solutions were prepared in $10 \mathrm{mM}$ Tris- $\mathrm{HCl}$ buffer $\mathrm{pH}$ 7.5. The buffer itself was prepared in double-autoclaved non-DEPC treated ultrapure Milli-Q type I water. It was observed that DEPC treated water results in undesirable redox peaks in electroanalytical experiments. The concentrated methylene blue solution was serially diluted to lower concentrations (e.g., 100, 50, 25 , $12.5 \mu \mathrm{M})$ using the same buffer as the diluent.

\section{Electrochemical measurements:}

The present device has been tested with a modified electrochemically active $\mathrm{TiO}_{2}: \mathrm{V}_{2} \mathrm{O}_{5}$ nanocomposite sensing layer. The electroanalytical signals were recorded using cyclic I-V measurement $(-1$ to $+1 \mathrm{~V}$ and back; scan rate $=40 \mathrm{mV} / \mathrm{s})$, and square-wave voltammetry (0 to $-1 \mathrm{~V}$; scan rate $=50 \mathrm{mV} / \mathrm{s}$ ) for multiple cycles.

\section{Primer optimization, fluorescence, and electrochemical LAMP assays}

The experiments concerning the LAMP primer optimization and assays have been described in detail in a separate manuscript from our groups currently undergoing peer review (uploaded with this manuscript ${ }^{40}$ ). Briefly, the LAMP assay involved $0.4 \mu \mathrm{M}$ outer primers, $0.332 \mu \mathrm{M}$ forward and 
backward inner primer, $1 \mu \mathrm{M}$ forward loop primers and $0.4 \mu \mathrm{M}$ back loop primers in their final concentration ${ }^{41}$ (sequences, F3: CGA TAA GTA TGT CCG CAA TT, B3: GCT TCA GAC ATA AAA ACA TTG T, FIP: ATG CGT AAA ACT CAT TCA CAA AGT CCA ACA CAGACT TTA TGA GTG TC, BIP: TGA TAC TCT CTG ACG ATG CTG TTT AAA GTT CTTTAT GCT AGC CAC, Loop F: TGT GTC AAC ATC TCT ATT TCT ATA G, Loop B: TCA ATA GCA CTT ATG CAT CTC AAG G). A $25 \mu \mathrm{L}$ LAMP assay also contained the following components in their respective final concentrations: $1 \times$ Bst 2.0 DNA polymerase reaction buffer [20 mM Tris- $\mathrm{HCl}, 50 \mathrm{mM} \mathrm{KCl}, 10 \mathrm{mM}\left(\mathrm{NH}_{4}\right)_{2} \mathrm{SO}_{4}, 2 \mathrm{mM}$ $\mathrm{MgSO}_{4}, 0.1 \%$ Tween-20, pH 8.8], dNTPs (1.4 mM), SYBR I (1× diluted from 10,000X stock), $8 \mathrm{U}$ of Bst 2.0 DNA polymerase, $\mathrm{MgSO}_{4} \quad(6 \quad \mathrm{mM})$, template (plasmid \#14567, https://www.addgene.org/145671/ or in vitro transcribed RNA, $1 \mu \mathrm{L}$ ) or magneto-extracted nucleic acid on beads $(2 \mu \mathrm{L})$. For electrochemical LAMP, the SYBR I was replaced with MB (final concentration $50 \mu \mathrm{M}$ ). For reverse transcription LAMP (RT-LAMP), the reaction was also added with $7 \mathrm{U}(0.25 \mu \mathrm{L})$ of reverse transcriptase RTx. The fluorescence LAMP and electrochemical LAMP were conducted in real-time PCR $\left(64^{\circ} \mathrm{C}\right.$ for $1 \mathrm{~h}$, with fluorescence monitoring every $1 \mathrm{~min}$, followed by melting curve analysis) or thermal cycler $\left(64^{\circ} \mathrm{C}\right.$ for $1 \mathrm{~h}$ followed by $85^{\circ} \mathrm{C}$ for $\left.20 \mathrm{~min}\right)$, respectively.

\section{In vitro transcription of SARS-CoV-2 RdRp RNA from plasmid and concentration} assessment

The experiments involving the in vitro transcription of SARS-CoV-2 RdRp RNA from plasmid and its concentration assessment is described in detail in a separate manuscript from our groups currently undergoing peer review (uploaded with this manuscript ${ }^{40}$ ). Briefly, the RdRp sequence bearing plasmid (\#14567, https://www.addgene.org/145671/) was linearized using the restriction enzyme SnaBI. The linearized plasmid was then treated with in vitro transcription kit, resulting in the generation of RdRp RNA. The RNA was subjected to cDNA formation. Simultaneously, the plasmid was utilized in generating a concentration vs $\mathrm{C}_{\mathrm{t}}$ (cycle threshold) standard curve generated using realtime PCR assays (forward primer: ACACAATGGCAGACCTCGTC and reverse primer: CAAAGCTTGGCGTACACGTT). The standard curve was then applied to assess the concentration of the cDNA, and in turn, the in vitro transcribed RNA.

\section{Magnetocapture of SARS-CoV-2 RdRp plasmid DNA and RNA}

In a separate manuscript from our groups currently undergoing peer review (uploaded with this manuscript ${ }^{40}$ ), we have demonstrated the utility of the indirect magnetocapture over the direct 
magnetocapture in terms of assay performance. The working scheme of the indirect magnetocapture, the one utilized in this manuscript has been illustrated in Figure 8. Briefly, $100-1000$ copies of target nucleic acid present in a $40 \mu \mathrm{L}$ aqueous solution, an aqueous solution containing $1 \mathrm{ng}$ human genomic DNA (extracted from MCF-7 cells) or 5\% (for RNA magnetocapture) - 10\% (for plasmid DNA magnetocapture) $\mathrm{v} / \mathrm{v}$ fetal bovine serum was incubated with a 5'-biotinylated probe nucleic acid. After heating $\left(65^{\circ} \mathrm{C} 2 \mathrm{~min}\right)$ and incubation in ice (15 min, for RNA) or room temperature (15 min, for plasmid DNA), the solution was incubated with $10 \mu \mathrm{L}$ streptavidin magnetic beads (15 min). After magnetic decantation wash (buffer composition $5 \mathrm{mM}$ Tris-HCl, $0.5 \mathrm{mM}$ EDTA, $1 \mathrm{M} \mathrm{NaCl}$, $\mathrm{pH} 7.5,200 \mu \mathrm{L}, 3$ washes), $2 \mu \mathrm{L}$ of the beads were subjected to LAMP assays as described above.

\section{Result and Discussion}

\section{Design and concept:}

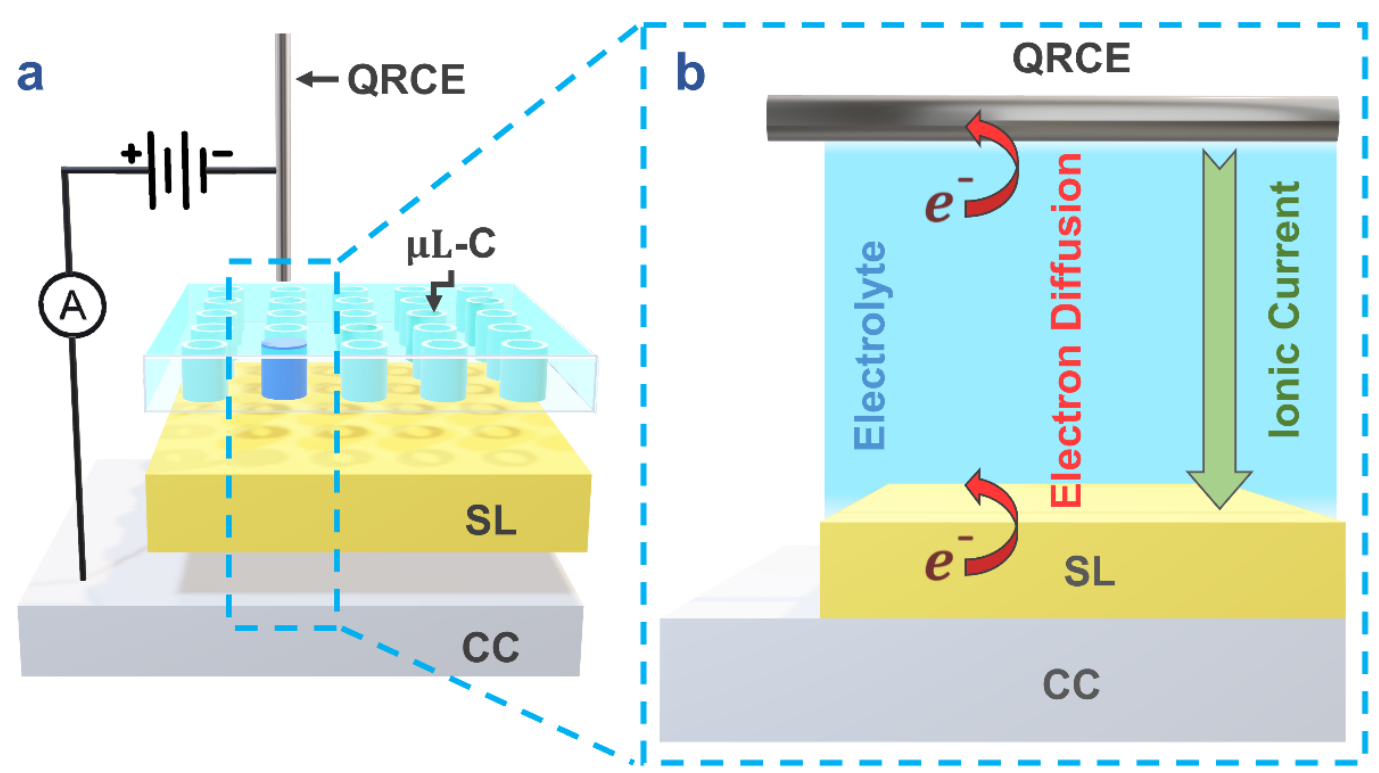

Figure 1 Electrode geometry and concept. (a) Dual electrode electrochemical sensor (DEES) schematic. (b) Charge transport kinetics (QRCE: quasi-reference counter electrode, $\mu L-C$ : microliter cavity $S L$ : sensing layer, CC: current collector).

The key factors responsible for the electrochemical activity of transition metal oxides (TMOs) are the electrode-electrolyte interface (e-e interface), electronic conductivity, and ionic diffusion. The TMOs can be tailored to achieve the desired electrochemical performance via various approaches one of which is combining two metal oxides to form a nanocomposite. The metal oxide nanocomposite (MO-NC) can effectively provide more active sites on the electrode surface, improve electronic conduction, and enhance the interfacial surface area. ${ }^{42}$ We conceptualize a binary MO-NC 
$\mathrm{TiO}_{2}: \mathrm{V}_{2} \mathrm{O}_{5}$ sensing layer for efficacious detection of nucleic acid by sensing the change in the ionic concentration of the reporter probe (methylene blue) as a result of nucleic acid amplification. We hypothesize that incorporating $\mathrm{TiO}_{2}$ into the $\mathrm{V}_{2} \mathrm{O}_{5}$ host matrix will improve the electrical conductivity of $\mathrm{V}_{2} \mathrm{O}_{5}$. The higher conductivity improves the charge transfer rate in the sensing layer, resulting in better sensitivity. The proposed device, utilizing a MO-NC, would thus measure minute changes in the electric transport through the system which is a combination of electronic and ionic charge transport.

In addition to the nanocomposite, we sought to explore the effect of surface charge on the electron transfer, and by extension, towards NAAT biosensing. When the working electrode was immersed in the electrolyte, depending on the surface isoelectric point (IEP) and solution $\mathrm{pH}$, an electric double layer (EDL) is formed. For $\mathrm{V}_{2} \mathrm{O}_{5}$ the IEP is reported to be $1.5-2.3^{43}$, in our case the electrolyte $\mathrm{pH}$ was 8.8 causing the cations to accumulate at the $\mathrm{V}_{2} \mathrm{O}_{5}$ surface. The reduced and oxidized species of the electrolyte were in equilibrium and no current was passed. ${ }^{44}$ On changing the potential, charge imbalance was caused across the interface and therefore, causing the ions inside the electrolyte solution to rearrange themselves to achieve a new equilibrium position, thereby initiating ionic conduction. To validate the effect of interaction between IEP and electrolyte $\mathrm{pH}$ as well as to nanocomposite fabrication, a dual-electrode TMO based electrochemical readout system is designed for the nucleic acid amplification tests (NAATs) at low cost, minimal processing and with a handy user interface. The sensor design has been discussed in our earlier reported work and schematically represented in Figure $1 \mathrm{a}^{35}$. An advantage of using the proposed DEES in comparison to commercial SPE electrodes is that for every test sample to be evaluated a separate SPE unit would be needed. Therefore, a bundle of SPEs would be required to perform any series measurements or to have a statistical dataset for any nucleic acid amplification. Whereas we fabricate $2.5 \times 2.5 \mathrm{~cm}$ working electrode in the proposed DEES with around 30 individual PDMS test cavities. This could be utilized to perform 30 measurements on a single fabricated electrode. Overall, the proposed DEES bielectrode geometry provides a biosensor assay for implementing multiple measurements on a single working electrode.

Consequently, the high current was rushed through the system (EDL charging current) and an intense current was recorded in the first cycle of every electroanalytical data measurement. During the voltage sweep, at a certain voltage when it was thermodynamically or kinetically favourable, electron 
migrates through the localized states across the e-e interface and an intense current peak (Faradaic current) was observed (Figure 1b). ${ }^{45,46}$ The Faradaic current is limited by the electronic conductivity of the electrode and the electrochemical activity of the surface. SI Figure 1 (20\%-TVO, red curve) presents two Faradaic peaks corresponding to reduction $(-0.4 \mathrm{~V})$ and oxidation $(-0.07 \mathrm{~V})$ of the redox probe (MB). The redox couple of MB is shown in SI Figure 2. Therefore, the net current density $\left(J_{n}\right)$ through the system is the combination of ionic $\left(J_{i}\right)$ and electronic $\left(J_{e}\right)$ current density, ${ }^{46}$

$$
\begin{aligned}
& J_{i}=q n_{i} \mu_{i} E-q D_{i} \frac{\partial n_{i}}{\partial x} \\
& J_{e}=q n_{e} \mu_{e} E+q D_{e} \frac{\partial n_{e}}{\partial x}
\end{aligned}
$$

Where, $\mathrm{q}, \mathrm{n}, \mu, \mathrm{E}$, and D represents the charge carriers, number of charge carriers, mobility, applied electric field, and coefficient of diffusion, respectively. When amplicon is present in the solution, the MB instead binds to the DNA using charge and intercalation. As a result, the electron transfer to the electrode is affected, causing a drop in current. This aspect could be utilized to quantitatively probe the concentration of the amplicon and in extension that of the target nucleic acid. 
Structural and compositional analysis

$X$-ray diffraction study:
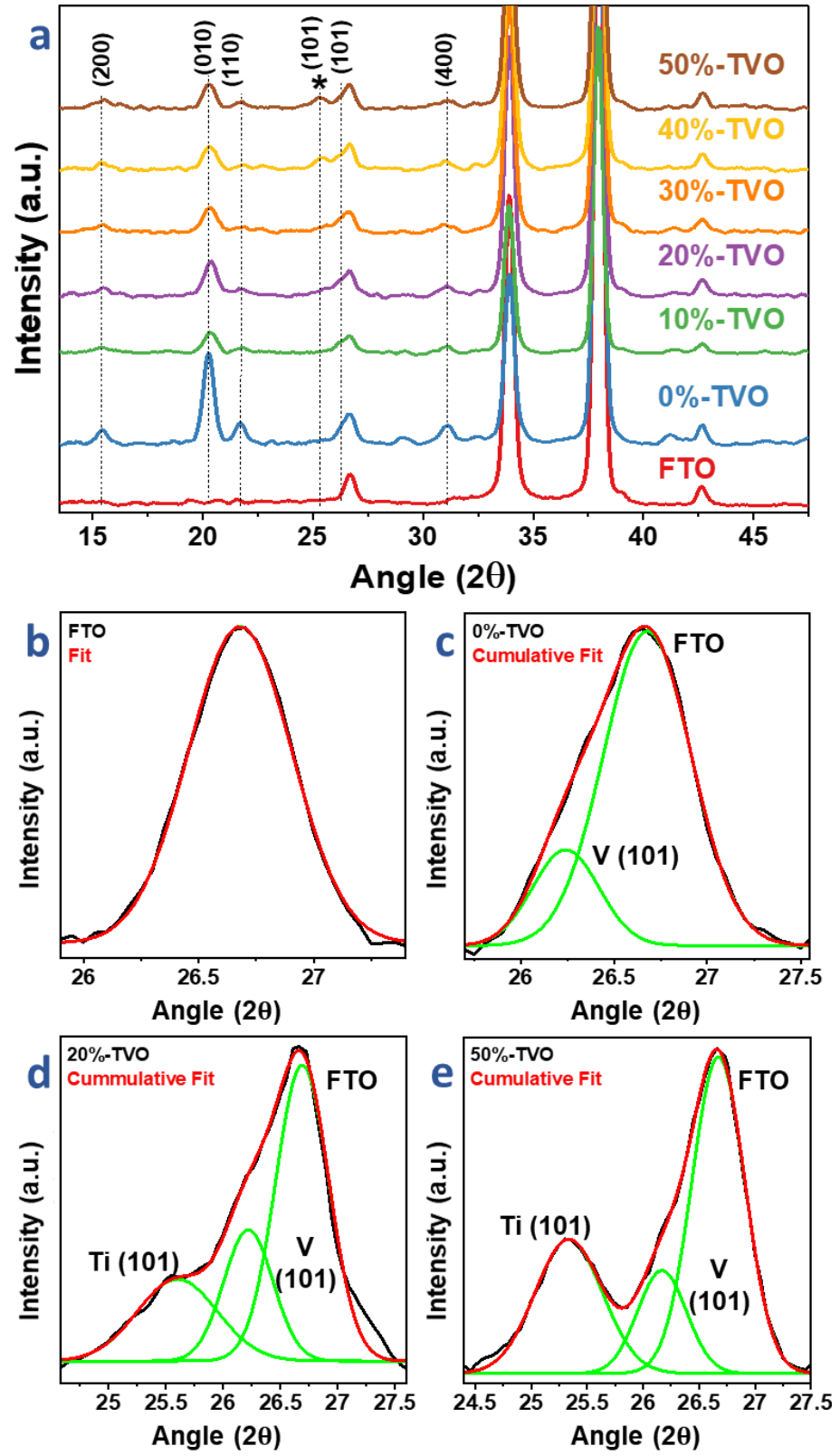

Figure 2 X-ray diffraction pattern. (a) XRD complete scan for bare FTO, and 0-50\%-TVO. (b-e) Deconvolution of $26.5^{\circ}$ peak into FTO, $V$, and Ti peaks for bare FTO, 0, 20, 50\%-TVO, respectively.

Next, the as-fabricated electrodes were probed with various characterization tools such as XRD, XPS, SEM, electrical and electrochemical techniques to examine and optimize the electrode for biosensing applications. The crystallinity of the sensing layer was investigated by X-ray diffraction (XRD) for a $2 \theta$ range of $10-90^{\circ}$ with $0.02^{\circ}$ step size. The analysis was done in grazing incidence mode $\left(\theta \approx 0.5^{\circ}\right)$ so that the crystal structure of the deposited thin film $(\sim 20 \mathrm{~nm})$ could be investigated. Figure $2 \mathrm{a}$ 
presents XRD patterns for 0\% to 50\%-TVO along with bare FTO (for reference). The peaks at $26.7^{\circ}$, $33.9^{\circ}$, and $37.95^{\circ}$ are characteristic peaks of FTO (JCPDS \#077-0452) corresponding to (110), (101), and (200) orientations, respectively. ${ }^{47}$ The peaks labelled in Figure $2 \mathrm{a}$ with their respective indices belongs to orthorhombic $\mathrm{V}_{2} \mathrm{O}_{5}$ XRD pattern (JCPDS \#001-0359) ${ }^{48}$ and characteristic peaks corresponding to any other phases are not observed. This suggests the absence of any secondary vanadium oxide phase within the XRD detection limit. The average crystallite size was calculated with the most intense $\mathrm{V}_{2} \mathrm{O}_{5}$ peak (010) using Debye Scherrer equation ${ }^{49}$ and found to be $0.205 \pm$ $0.022 \mathrm{~nm}\left(2.05 \AA\right.$ A) (SI Table 1). The peak around $26.5^{\circ}$ was observed to be a result of multiple peak overlapping, therefore the peak was separately analysed in Figure 2b-e for the case of bare FTO, 0, 20, and 50\%-TVO (refer SI Figure 3 for 10, 30, and 40\%-TVO electrodes). The bare FTO consists of a single peak relating to FTO (110) orientation whereas a second peak corresponding to Vanadium (V) (101) orientation was observed for 0\%-TVO (Figure 2b, c). For 10\%-TVO a shoulder peak was detected relating to the signature peak of the tetragonal (anatase) $\mathrm{TiO}_{2}$ phase (JCPDF \# 021-1276) ${ }^{50}$. The peak becomes more prominent with the increasing $\mathrm{Ti}$ concentration and a separate $\mathrm{TiO}_{2}$ peak can be observed for 40, and 50\%-TVO (Figure $2 \mathrm{a}$ ) as indicated by the (*) symbol. This shows the gradual incorporation of $\mathrm{TiO}_{2}$ in the parent matrix of $\mathrm{V}_{2} \mathrm{O}_{5}$. The presence of two separate crystalline phases for $\mathrm{V}_{2} \mathrm{O}_{5}$ and $\mathrm{TiO}_{2}$ for all the $\mathrm{TiO}_{2}$ concentrations confirm the formation of metal oxide composite. 

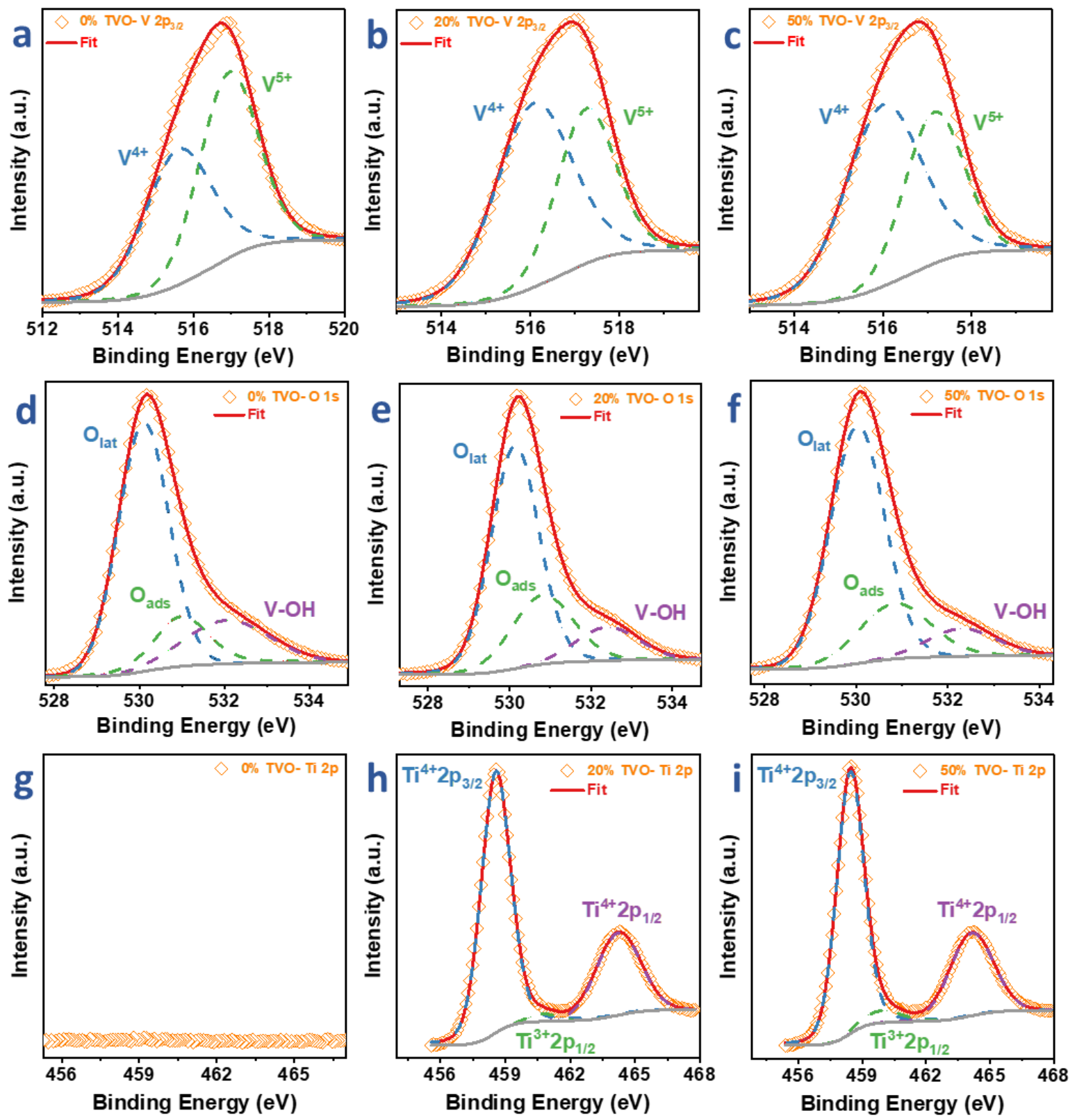

Figure 3 X-ray photoelectron spectroscopy analysis. (a-c) V 2p3/2, (d-f) O 1s, (g-i) Ti $2 p$ for 0, 20, and 50\%-TVO electrodes, respectively.

To examine the surface composition and oxidation state of the sensing layer X-ray photoelectron spectroscopy (XPS) was performed. The high-resolution XPS spectra for 0, 20, and 50\%-TVO are presented in Figure 3 (refer to SI Figure 4 for XPS spectra of 10, 30, and 40\%-TVO). All the spectral data were fitted using Lorentzian-Gaussian curves following Shirley-type background subtraction. The binding energy (BE) values and percent proportion $(\delta(\%))$ of various peaks are presented in Table 1. 
Table 1 Binding energy (B.E.) and percent portion ( $\delta(\%)$ ) of the V2p3/2, O1s, Ti2p peaks for the titanium oxide-vanadium oxide $(T V O)$ nanocomposite films with different Ti mol\%. $(\delta(\%)=$ peak area*100/total curve area; the area was considered after background subtraction).

\begin{tabular}{|c|c|c|c|c|c|c|c|c|c|c|}
\hline \multirow{4}{*}{$\begin{array}{c}X \\
\text { (X\% } \\
\text { TVO) }\end{array}$} & \multicolumn{4}{|c|}{ V 2p3/2 } & \multicolumn{4}{|c|}{ O 1s } & \multirow{2}{*}{\multicolumn{2}{|c|}{$\frac{\text { Ti 2p }}{\text { Ti (III) }}$}} \\
\hline & \multicolumn{2}{|c|}{$\mathbf{V}(\mathbf{I V})$} & \multicolumn{2}{|c|}{$\mathbf{V}(\mathbf{V})$} & \multicolumn{2}{|c|}{ Olat $_{\text {lat }}$} & \multicolumn{2}{|c|}{$\mathbf{O}_{\text {ads }}$} & & \\
\hline & \multirow{2}{*}{$\begin{array}{c}\text { BE } \\
(\mathbf{e V})\end{array}$} & \multirow{2}{*}{$\begin{array}{c}\delta_{1} \\
(\%)\end{array}$} & \multirow{2}{*}{$\begin{array}{l}\text { BE } \\
(e V)\end{array}$} & \multirow{2}{*}{$\begin{array}{c}\delta_{2} \\
(\%)\end{array}$} & \multirow{2}{*}{$\begin{array}{c}\text { BE } \\
(\mathbf{e V})\end{array}$} & \multirow{2}{*}{$\begin{array}{c}\delta_{1} \\
(\%)\end{array}$} & \multirow{2}{*}{$\begin{array}{c}\text { BE } \\
(\mathbf{e V})\end{array}$} & \multirow{2}{*}{$\begin{array}{c}\delta_{2} \\
(\%)\end{array}$} & $2 \mathbf{p}_{1 / 2}$ & \multirow{2}{*}{$\Delta_{2 p}$} \\
\hline & & & & & & & & & $2 p_{3 / 2}$ & \\
\hline $0 \%$ & 515.68 & 46.01 & 516.98 & 53.99 & 530.08 & 65.68 & 530.98 & 15.31 & --- & --- \\
\hline \multirow{2}{*}{$10 \%$} & \multirow{2}{*}{516.28} & \multirow{2}{*}{41.51} & \multirow{2}{*}{517.28} & \multirow{2}{*}{58.49} & \multirow{2}{*}{530.08} & \multirow{2}{*}{64.69} & \multirow{2}{*}{530.88} & \multirow{2}{*}{18.78} & 464.08 & \multirow{2}{*}{5.6} \\
\hline & & & & & & & & & 458.48 & \\
\hline \multirow{2}{*}{$20 \%$} & \multirow{2}{*}{516.18} & \multirow{2}{*}{61.15} & \multirow{2}{*}{517.28} & \multirow{2}{*}{38.85} & \multirow{2}{*}{530.18} & \multirow{2}{*}{63.19} & \multirow{2}{*}{530.78} & \multirow{2}{*}{24.87} & 464.28 & 57 \\
\hline & & & & & & & & & 458.58 & 5.1 \\
\hline $30 \%$ & 51628 & 5890 & 51748 & 4110 & 53018 & 6083 & 53088 & 2058 & 464.38 & 57 \\
\hline $50 \%$ & 310.28 & 58.90 & $51 / .48$ & 41.10 & 530.18 & 00.83 & 530.88 & 20.58 & 458.68 & 5.1 \\
\hline $40 \%$ & 51578 & 5826 & 51608 & 4174 & 52098 & 6049 & 53088 & 2262 & 464.18 & 58 \\
\hline $40 \%$ & & 58.20 & 510.98 & 41.14 & & 09.49 & & 22.02 & 458.38 & 5.8 \\
\hline$=007$ & 51600 & 61 & 51710 & 2020 & 52000 & 1002 & 52000 & ? & 464.18 & 57 \\
\hline $50 \%$ & 310.08 & 01.01 & 517.18 & 38.38 & 530.08 & 08.83 & 530.88 & 21.22 & 458.48 & 5.1 \\
\hline
\end{tabular}

Figure 3a-c shows vanadium $2 \mathrm{p}_{3 / 2}$ peak deconvoluted into two peaks at $\sim 516.05$ and $\sim 517.2 \mathrm{eV}$ corresponding to $\mathrm{V}^{4+}$ and $\mathrm{V}^{5+}$ oxidation state ${ }^{51,52,53}$, respectively, this confirmed the presence of mixed oxides of vanadium $\mathrm{VO}_{2}$ and $\mathrm{V}_{2} \mathrm{O}_{5}$. At ambient atmosphere, oxygen gets readily absorbed on the surface leading to higher $\mathrm{V}^{5+}$ contribution $(\sim 54 \%)$ in $0 \%$-TVO (table 1$)$. After Ti incorporation, oxidation of $\mathrm{V}$ was prevented and the contributions $\mathrm{V}^{5+}$ component was therefore reduced to $~ 39 \%$ for $20 \%$-TVO and similar for higher Ti concentration (table 1). The presence of the $\mathrm{VO}_{2}$ phase was not detected in the XRD analysis. Figure 3d-f shows oxygen 1s peak deconvoluted into three peaks at $\sim 530.09, \sim 530.9$ and $\sim 532.3 \mathrm{eV}$ corresponding to lattice oxygen $\left(\mathrm{O}_{\text {lat }}\right)$, adsorbed oxygen $\left(\mathrm{O}_{\text {ads }}\right)$, and $\mathrm{V}-\mathrm{OH}$, respectively ${ }^{51,53,54}$. It was complex to assign lattice oxygen peak to $\mathrm{V}-\mathrm{O}$ species or Ti-O species as both peaks have the $\mathrm{BE}$ values in the same range of $\mathrm{BE}{ }^{52}$. Various experimental observations have suggested that the amount of adsorbed oxygen species is directly proportional to the amount of oxygen vacant sites $\left(\mathrm{O}_{\mathrm{vac}}\right)^{55,56}$. A DFT study predicted that the $\mathrm{O}_{\text {ads }}$ species coupled with $\mathrm{O}_{\text {vac }}$ may possibly be modified to $\mathrm{O}^{-57}$. Therefore, a higher concentration of $\mathrm{O}_{\text {ads }}$ species results in higher electronic concentration that causes improved conduction. From Table 1, 20\%-TVO has the highest $\mathrm{O}_{\text {ads }}$ component $(24.87 \%)$ and must therefore possess optimum electrical conduction. Figure 3g-I shows Ti 2p peaks (except for 0\%-TVO) deconvoluted into three peaks at BE of $\sim 458.5$, 
$\sim 464.2$, and $\sim 460.12 \mathrm{eV}$ corresponding to $\mathrm{Ti}^{4+} 2 \mathrm{p}_{3 / 2}, \mathrm{Ti}^{4+} 2 \mathrm{p}_{1 / 2}$, and $\mathrm{Ti}^{3+} 2 \mathrm{p}_{1 / 2}$, respectively. ${ }^{54} \mathrm{The}^{2}$ spin-orbit parameter $\left(\Delta_{2 p}\right)$ equals to that of $\mathrm{TiO}_{2}\left(\Delta_{\mathrm{TiO}_{2}} \sim 5.7 \mathrm{eV}\right)$ and not to Ti-metal $\left(\Delta_{\text {metal }}=6.1\right.$ $\mathrm{eV})$ this confirmed that the $\mathrm{Ti}$ is present in its oxide form $\left(\mathrm{Ti}^{4+}\right.$, dominantly). ${ }^{58}$ Also, the shoulder peak of $\mathrm{Ti}^{3+}$ indicates the presence of $\mathrm{Ti}_{2} \mathrm{O}_{3}$.

Surface morphological analysis and film-substrate junction electrical analysis:
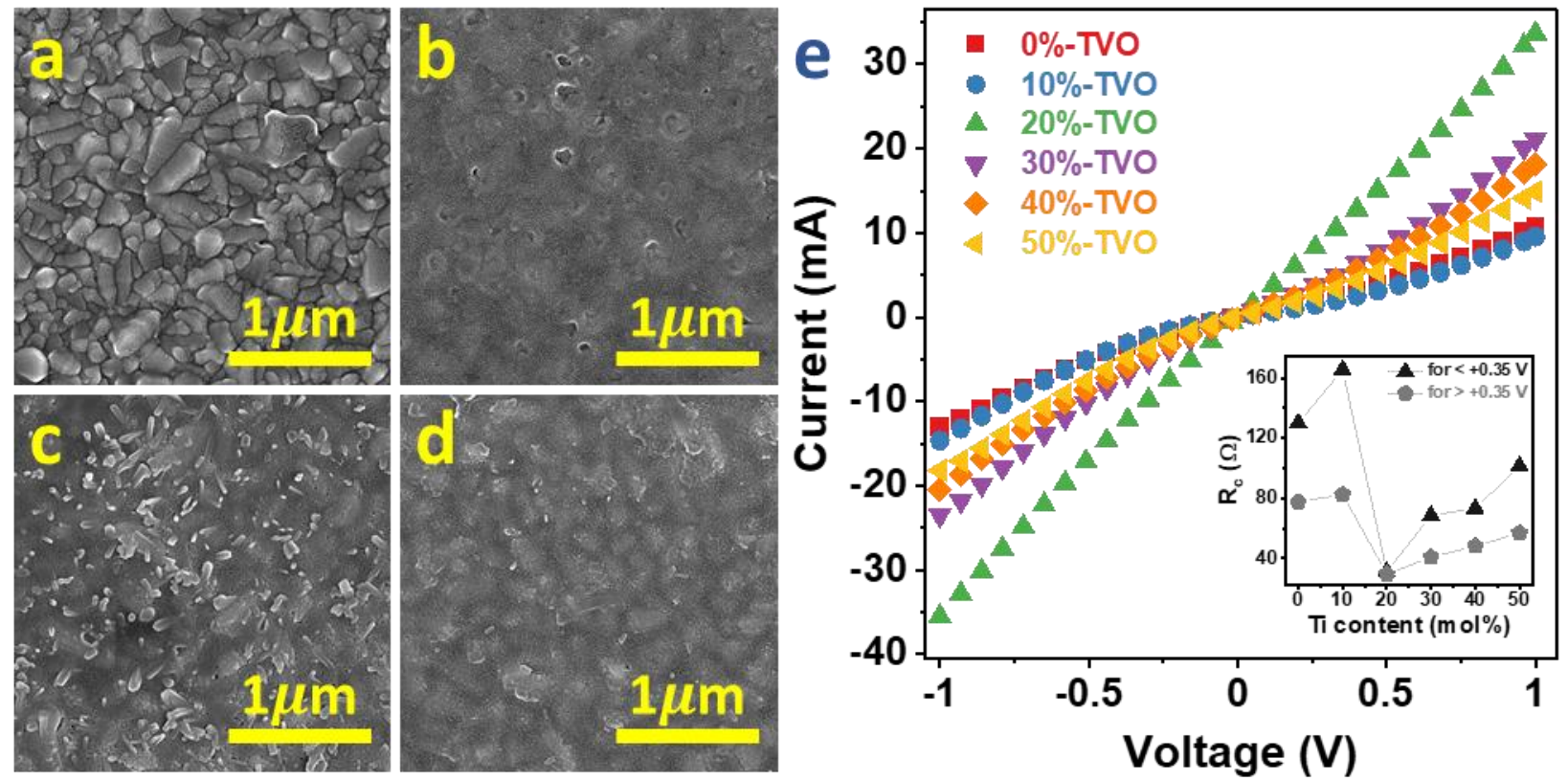

Figure 4 Morphological and electrical characterisation of the fabricated electrode. (a-d) FE-SEM images of bare FTO, 0, 20, and 50\%-TVO, respectively. (e) I-V characteristics of FTO-TVO junction for all fabricated electrodes

Next, we investigated the surface morphology of the electrodes using FE-SEM measurements. Figure 4 (a-d) shows the top view FE-SEM image of bare FTO, 0, 20, and 50\%-TVO, respectively. The surface morphology of FTO (Figure 4a) appears compact and covers the entire glass surface. Most grains are irregularly shaped and can be predominantly categorized in grain sizes of $\sim 200$ and $\sim 450$ $\mathrm{nm}$. Note that this is the standard morphology for the FTO layer over a glass substrate. ${ }^{59,60}$ The asfabricated 0\%-TVO film appears featureless, but as the Ti content increased to $10 \mathrm{~mol} \%$ (Figure $4 \mathrm{~b}$ and SI Figure 5a) a random pattern was visible along with a few "nanostrips" like structures. As the content increased to $20 \mathrm{~mol} \%$-Ti (Figure 4c) the "nanostrips" structure became more prominent having an approximate length of $126 \mathrm{~nm}$. The nanostructured electrode improves the electrochemical reaction rate owing to its increased surface-to-volume ratio, thus increasing the electrode surface active sites to the analyte. ${ }^{6}$ Further, with an increase in the Ti content from 30 to 50 mol\% (Figure $4 \mathrm{~d}$ and SI Figure 5b-d), the surface morphology appears to be more granular. The layer thickness was 
evaluated using the surface profilometer and the corresponding surface profiles and thickness values are presented in SI Figure 6 and SI Table 1, respectively. It was observed that the layer thickness increased very marginally with Ti content and the average thickness was $19.88 \mathrm{~nm}$ with a very slight deviation of $\pm 2.09 \mathrm{~nm}$ from the mean value. This implies that any electrical or electrochemical characteristics of the deposited layer would not be a consequence of its thickness.

To study the impact of increasing Ti content on the electrical character of the sensing layer, currentvoltage (I-V) characteristics of TVO/FTO junction were recorded for all the variants using SMU (Figure $4 \mathrm{e}$ ). The voltage was swept in the range of -1 to $+1 \mathrm{~V}$ and the measured current value presented was averaged over $n=3$ replicates. The slope of the I-V curves was observed to be increasing as the electrode composition is varied from pristine $\mathrm{V}_{2} \mathrm{O}_{5}(0 \%$-TVO) to $20 \mathrm{~mol} \% \mathrm{Ti}$ content $\mathrm{V}_{2} \mathrm{O}_{5}(20 \%$-TVO), and again reduced to a lower value for higher Ti mol\%. The curves are all nearly linear throughout excluding a small range from -0.35 to $+0.35 \mathrm{~V}$. The calculated contact resistance $\left(R_{c}\right)$ values on either side of $+0.35 \mathrm{~V}$ are distinct, with the $R_{c}$ value reducing at higher voltage (Figure 4e (inset plot)). This indicates the presence of an interfacial Schottky barrier at the TVO/FTO junction that required $0.35 \mathrm{~V}$ to overcome. The curve for $20 \%$-TVO shows a nearly-ohmic behaviour with an $R_{c}$ value nearly equal on either side of $+0.35 \mathrm{~V}$. This suggests that optimal electrical conduction has been achieved with $20 \mathrm{~mol} \% \mathrm{Ti}$ as suggested by the XPS results. This could be the result of an interplay between the Ti acceptor lowering the number of charge carriers and $\mathrm{O}_{\mathrm{vac}}$ introducing donors into the lattice matrix. As reported by XPS data 20\%-TVO had the highest $\mathrm{O}_{\text {ads }}$ percent proportion implying the highest content of $\mathrm{O}_{\mathrm{vac}}$ (table 1). Overall, the electrical conductivity analysis was in agreement with the XPS analysis. 
Electrode optimization:

Electrochemical impedance spectroscopy (EIS) study:
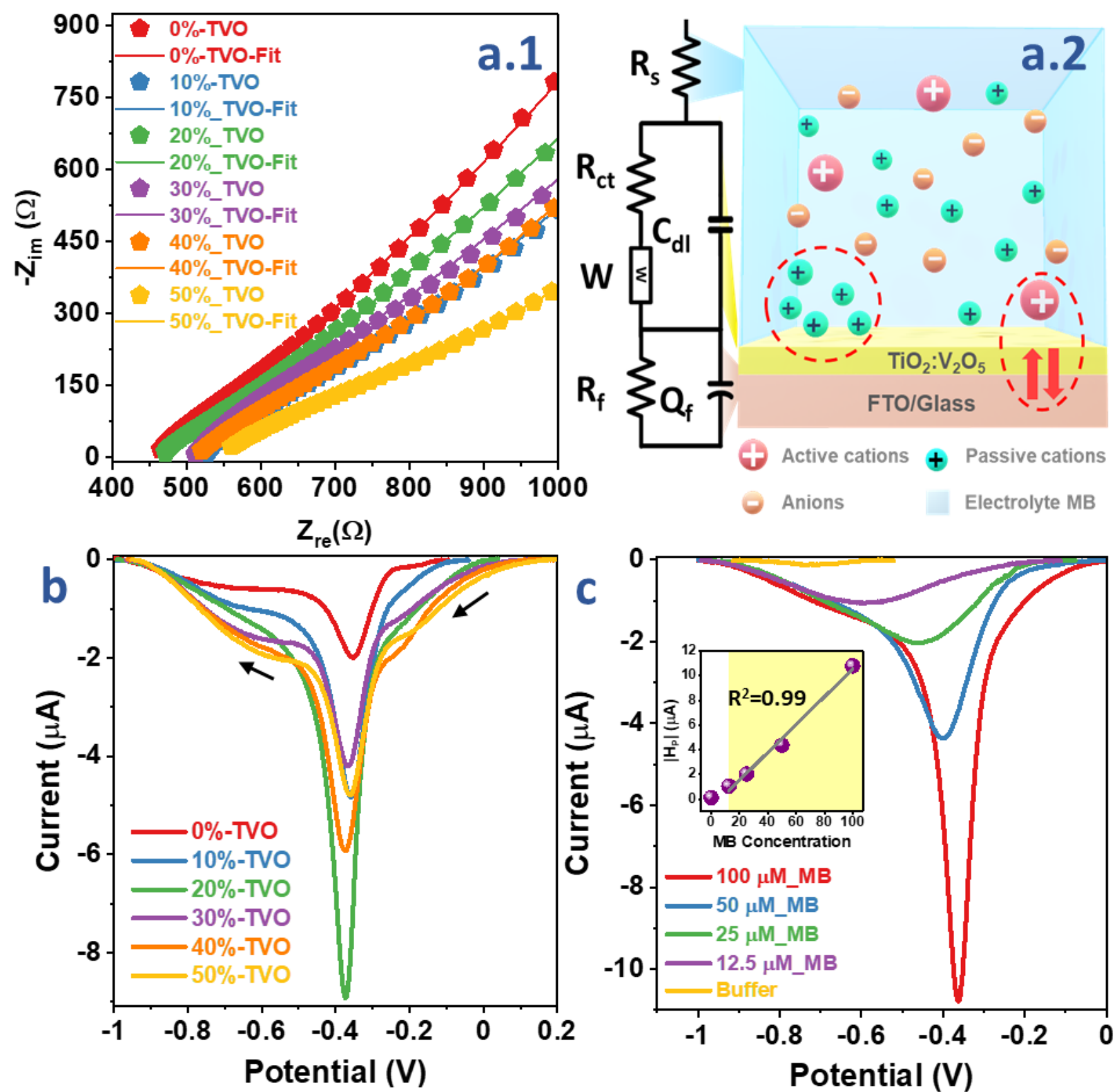

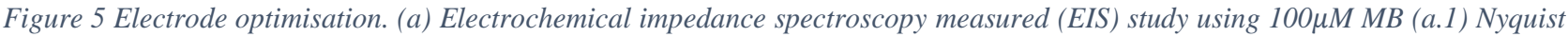
plot, (a.2) Schematic representation of charge transfer at the electrode-electrolyte interface and its equivalent electrical circuit diagram. (b) I-V characteristics (baseline corrected) evaluating the performance of $0 \%$ to $50 \%$ TVO devices for $100 \mu M M B$ (arrows indicates the direction of the voltage scan). (c) I-V characteristics (baseline corrected) showing the response of 20\%-TVO towards various $M B$ concentrations, each curve is an average of $n=5$ cycles (inset: calibration curve showing MB concentration vs. peak height $\left.\left(H_{P}\right)\right)$. 
Table 2 Equivalent circuit parameters for 0 to 50\%-TVO electrodes according to the EIS spectra shown in Figure 5 a.

\begin{tabular}{|c|c|c|c|c|c|c|c|}
\hline Element & Parameter & $\mathbf{0 \%}$ & $\mathbf{1 0 \%}$ & $\mathbf{2 0 \%}$ & $\mathbf{3 0 \%}$ & $\mathbf{4 0 \%}$ & $\mathbf{5 0 \%}$ \\
\hline $\mathbf{R}_{\mathbf{s}}(\boldsymbol{\Omega})$ & $\mathbf{R}$ & 440.24 & 609.15 & 307.06 & 619.03 & 499.51 & 529.87 \\
\hline $\mathbf{C}_{\mathbf{d l}}(\boldsymbol{\mu} \boldsymbol{F})$ & $\mathbf{C}$ & 3.12 & 7.34 & 4.24 & 5.60 & 6.14 & 7.15 \\
\hline $\mathbf{R}_{\mathbf{c t}}(\boldsymbol{\Omega})$ & $\mathbf{R}$ & 917 & 858 & 352 & 430 & 677 & 760 \\
\hline $\mathbf{W}$ & $\mathbf{Y}_{\mathbf{0}}\left(\boldsymbol{\mu} \boldsymbol{S} * \boldsymbol{s}^{\mathbf{1} / \mathbf{2}}\right)$ & 7.84 & 21.1 & 44.4 & 26.1 & 16.2 & 32.6 \\
\hline \multirow{2}{*}{$\mathbf{Q}_{\mathbf{f}}$} & $\mathbf{Y}_{\mathbf{0}}\left(\boldsymbol{\mu} \boldsymbol{S} * \boldsymbol{s}^{\boldsymbol{n}}\right)$ & 39.2 & 48.3 & 54.1 & 34.0 & 55.3 & 56.3 \\
\cline { 2 - 8 } & $\boldsymbol{n}$ & 0.50 & 0.52 & 0.53 & 0.57 & 0.49 & 0.45 \\
\hline $\mathbf{R}_{\mathbf{f}}(\mathbf{k} \boldsymbol{\Omega})$ & $\mathbf{R}$ & 9.343 & 1.233 & 0.59 & 1.152 & 1.403 & 1.243 \\
\hline & $\boldsymbol{\chi}^{\mathbf{2}}$ & 0.012 & 0.006 & 0.016 & 0.006 & 0.044 & 0.008 \\
\hline
\end{tabular}

Electrochemical impedance spectroscopy (EIS) was performed to electrically map the sensor geometry using passive circuit elements to facilitate analysis of various phases of charge transfer that responds at different $A C$ frequencies. Considering the entire system, intrinsic resistance $\left(\mathrm{R}_{\mathrm{s}}\right)$ of the electrolyte, double-layer capacitance $\left(\mathrm{C}_{\mathrm{dl}}\right)$ resulting from the passive ions that alters the surface charge distribution, and Faradaic impedance $\left(\mathrm{Z}_{\mathrm{f}}\right)$ encountered by the active ions during charge exchange at the e-e interface were anticipated. Figure 5(a.1) shows EIS data (Nyquist plot) for all the six electrodes fitted to an equivalent electrical circuit (EEC) presented in Figure 5(a.2). As shown in the EEC, Faradaic impedance $\left(\mathrm{Z}_{\mathrm{f}}\right)$ is mapped using a series combination of charge transfer resistance $\left(\mathrm{R}_{\mathrm{ct}}\right)$ and Warburg impedance $(\mathrm{W})$. The EEC is the modified version of the well-known Randles circuit with an additional time constant to model the sensing layer. ${ }^{61,62}$ Since the sensing layer was semiconducting in nature, it contributed a considerable layer resistance. It has been observed that only after incorporating the layer/film impedance, the experimental data and the fit could reach a good agreement. The layer/film impedance consists of a parallel combination of resistance $\left(\mathrm{R}_{\mathrm{f}}\right)$ and a constant phase element $\left(\mathrm{Q}_{\mathrm{f}}\right)$. The $\mathrm{Q}_{\mathrm{f}}$ accounted for surface inhomogeneity and roughness of the sensing layer. All the fitting parameter values have been presented in Table 2 for electrodes with various $\mathrm{Ti}$ content. The $\mathrm{R}_{\mathrm{ct}}$, for all electrode variants, contributes only a small portion to the total resistance, while the layer resistance $\left(\mathrm{R}_{\mathrm{f}}\right)$ dominantly defines the final resistance to charge exchange. The lowest $\mathrm{R}_{\mathrm{f}}$ value for $20 \%$-TVO $(590 \Omega$ ) indicates the highest conductivity and easier charge transfer at the e-e interface. The admittance $\left(\mathrm{Y}_{0}\right)$ value for both $\mathrm{W}$ and $\mathrm{Q}_{\mathrm{f}}$ are highest for 20\%-TVO, supporting good conductivity. The average $n$-value of $\mathrm{Q}_{\mathrm{f}}$ for all the electrodes is $0.51( \pm 0.045)$ that shows an equal resistive and capacitive component in the characteristics of a $\mathrm{Q}_{\mathrm{f}}$ supporting its 
inevitability. The fitting applicability and a lower $\chi^{2}$ value (Table 2) validates the chosen EEC. The Bode plots for all the electrodes are shown in SI Figure 7, demonstrating good agreement between the experimental and fitted data. The impedance value indicated by the curve is consistent with that observed by the Nyquist plot having the lowest value for $20 \%$-TVO.

\section{Electroanalytical response (I-V characteristics):}

Next, all the fabricated electrodes with varying Ti content were tested for their electroanalytical performance towards MB reduction. I-V measurements were performed using SMU by sweeping a voltage from $-1 \mathrm{~V}$ to $+1 \mathrm{~V}$ and back for 6 consecutive cycles and the average current values for 5 cycles is plotted. The first cycle was not considered because of high current intensity dominantly due to electric double layer (EDL) charging. Figure 5b shows I-V characteristics of $0 \%$ to $50 \%$ TVO for $100 \mu \mathrm{M}$ MB after subtracting a baseline connecting the two extremes of the reduction peak around $0.36 \mathrm{~V}$. The peak intensity was lowest for pristine $\mathrm{V}_{2} \mathrm{O}_{5}(0 \%-\mathrm{TVO})$, and it increased linearly to its maximum value for $20 \%$-TVO and again gradually decreased for higher Ti content. This was in continuation of the same trend observed for electrical conductivity and EIS measurements. The superior electrochemical activity of $20 \%$-TVO was plausibly due to the optimum electronic conductivity of the electrode that aided the efficient charge transfer at the e-e interface. Based on the excellent structural, electrical, and electroanalytical properties of $20 \%$-TVO, this electrode was selected to be utilized in (bio)sensing applications.

\section{Probe validation:}

To evaluate the electrochemical interaction of methylene blue (MB) with 20\%-TVO I-V characteristics (Figure 5c) and chronoamperometry (CA) (SI Figure 8a) were recorded for various concentrations of $\mathrm{MB}(100,50,25$, and $12.5 \mu \mathrm{M})$. For I-V characteristics, the cathodic current peak was considered for analysis and the corresponding voltage value was applied for recording CA for $300 \mathrm{sec}$. The high probe concentration enhances the ionic conductivity of the system which therefore yields a higher current signal (-10.78 $\mu \mathrm{A}$ for $100 \mu \mathrm{M} \mathrm{MB})$ (Figure5c). The peak current intensity reduces linearly with probe dilution to $-1.053 \mu \mathrm{A}$ for $12.5 \mu \mathrm{M} \mathrm{MB}$. The inset Figure $5 \mathrm{c}$ is a plot of absolute peak current value versus MB concentration including trendline and $\mathrm{R}$-squared value $\left(\mathrm{R}^{2}=\right.$ 0.99) suggesting linear relation over the complete concentration range. it was also supported by the linearity of the calibration curve (SI Figure $8 b)$ obtained from CA data $\left(\mathrm{R}^{2}=0.98\right)$. Analyzing the IV characteristics of $20 \%$-TVO for MB $(100 \mu \mathrm{M})$, and buffer alone solution revealed the presence of 
considerable electrical double layer (EDL) capacitance (non-Faradaic current) as shown in SI fig 9 63 . To reduce the contribution of this charging current and to improve Faradaic current sensitivity towards probe concentration, we opted for square wave voltammetry (SWV) for NAATs detection ${ }^{64}$.

Next, the electroanalytical response of the proposed 20\%-TVO electrode was compared with that of our previously reported $\mathrm{MnO}_{2}$ bi-electrode system ${ }^{35}$. As mentioned earlier, the lower IEP $\left(1.5-2.3^{43}\right)$ of the TVO layer should attract more positively charged MB from the electrolyte $(\mathrm{pH} 7.5$ for buffer and $\mathrm{pH} 8.8$ for amplification) compared to the $\mathrm{MnO}_{2}$ system (IEP $4-5^{37}$ ). In principle, this should cause a higher current signal for the former. To validate this hypothesis, we compared the electroanalytical response (I-V characteristics) of 20\%-TVO with our previously reported $\mathrm{MnO}_{2}$ electrode (FM550) for 100 $\mu \mathrm{M}$ concentration of MB (SI Figure 10). The experiment demonstrated that the MB reduction peak intensity of FM550 was merely $43 \%$ of that of $20 \%$-TVO, thus clearly validating our hypothesis about the enhanced electrochemical activity of the present electrode over the previous $\mathrm{MnO}_{2}$ based electrode. 
NAATs detection of LAMP products

Electrochemical read-out using fabricated TVO electrode
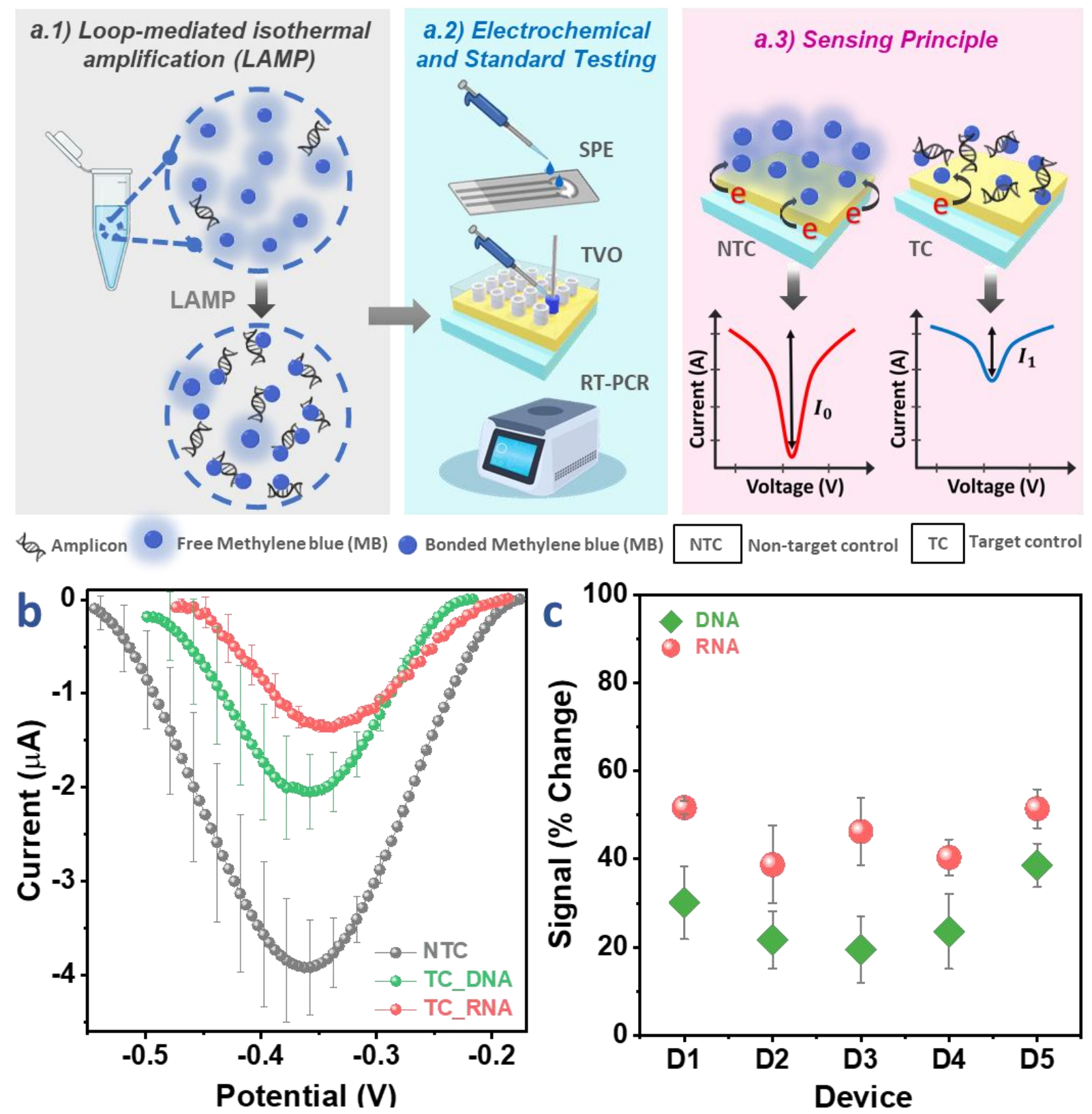

Figure 6 NAATs detection of LAMP products (a) Schematic representation of LAMP, electrochemical and standard testing of LAMP products, and the detector sensing principle. (b) SWV (baseline corrected) for NTC and TC (DNA, and RNA) for LAMP reaction (MB concentration $50 \mu \mathrm{M}$, initial nucleic acid concentration $10^{3}$ copies) averaged over $n=3$ replicates. (c) Statistical data showing \% change before and after amplification for 5 different devices for LMAP reactions averaged over $n=3$ replicates on each device.

After characterization and optimization, the 20\%-TVO electrode was used for electrochemical detection of SARS-CoV-2 RdRp plasmid DNA and in vitro transcribed RNA in an aqueous solution using isothermal amplification (LAMP). The LAMP primer optimization, in vitro transcription, and 
RNA concentration determination has been described briefly in the materials and methods section and in more detail in a separate manuscript focusing on the magnetocapture aspect of the project (currently undergoing peer review, uploaded with this manuscript ${ }^{40}$ ). Figure 6 a schematically represents (1) the LAMP amplification, (2) the tools used for detecting the amplification, and (3) the sensing principle. In the case of no template control (NTC, negative control), the amplicon concentration was very limited due to the absence of a template. The high redox current so obtained was generated due to the rapid diffusion of free MB molecules at the electrode surface. For the case of template control (TC, i.e., positive control) sample, millions of amplicons were produced after amplification that interacts with MB molecules via intercalation into amplicon, hydrogen bonding ${ }^{65}$, and electrostatic interactions between the cationic MB molecule and negatively charged phosphate DNA backbone ${ }^{66}$. Thus, the amplicon sequestered the available MB which consequently reduces the current signal. Figure $6 \mathrm{~b}$ presents the sensor response for NTC and TC reaction products with the initial concentration of $10^{3}$ target copies for both DNA and RNA. The electrochemical amplification response was gauged based on absolute current magnitude for the target analyte and NTC sample as shown in Figure $6 \mathrm{~b}$. The significant change in cathodic peak current $(\Delta \mathrm{I})$ was observed for both DNA $(1.87 \mu \mathrm{A})$ and RNA $(2.56 \mu \mathrm{A})$, the data points and the error bars represent the average of 3 consecutive cycles and the corresponding standard deviation, respectively. For the current changebased detection, we have defined a sensing signal S(I) to calculate percent change in the magnitude of current after amplification,

$$
\mathrm{S}(\mathrm{I})=\frac{\mathrm{I}_{0}-\mathrm{I}_{1}}{\mathrm{I}_{0}} * 100 \%
$$

Where, $\mathrm{I}_{0}$ and $\mathrm{I}_{1}$ denotes peak current value for NTC and TC, respectively. The signal $\mathrm{S}(\mathrm{I})$ and absolute current response (for a target analyte and NTC) were hence used to evaluate sensor capability for NAATs as well as a qualitative measure of the degree of amplification. The NAAT was performed on 5 separate sensing devices for DNA and RNA each (with 20\%-TVO as a working electrode) for statistical analysis (Figure 6c). For the case of DNA amplification, the average \%change $(\mathrm{S}(\mathrm{I}))$ was observed to be $26.67 \%( \pm 7.77)$ whereas, it was $45.71 \%( \pm 6.04)$ for RNA amplification. The coefficient of variation was $13.2 \%$ and $29.1 \%$ for RNA and DNA LAMP detection, respectively. Another approach for NAAT is using chronoamperometry (CA, SI Figure 11 ), where the $\Delta \mathrm{I}$ value calculated for 100 seconds after the current reached its saturation value for 
NTC and TC (with plasmid DNA) was $394 \mathrm{nA}$. While the $\Delta \mathrm{I}$ from CA can also be used as a measure for detection, it was not further explored in the present work.

\section{Limit of detection (LOD) study:}
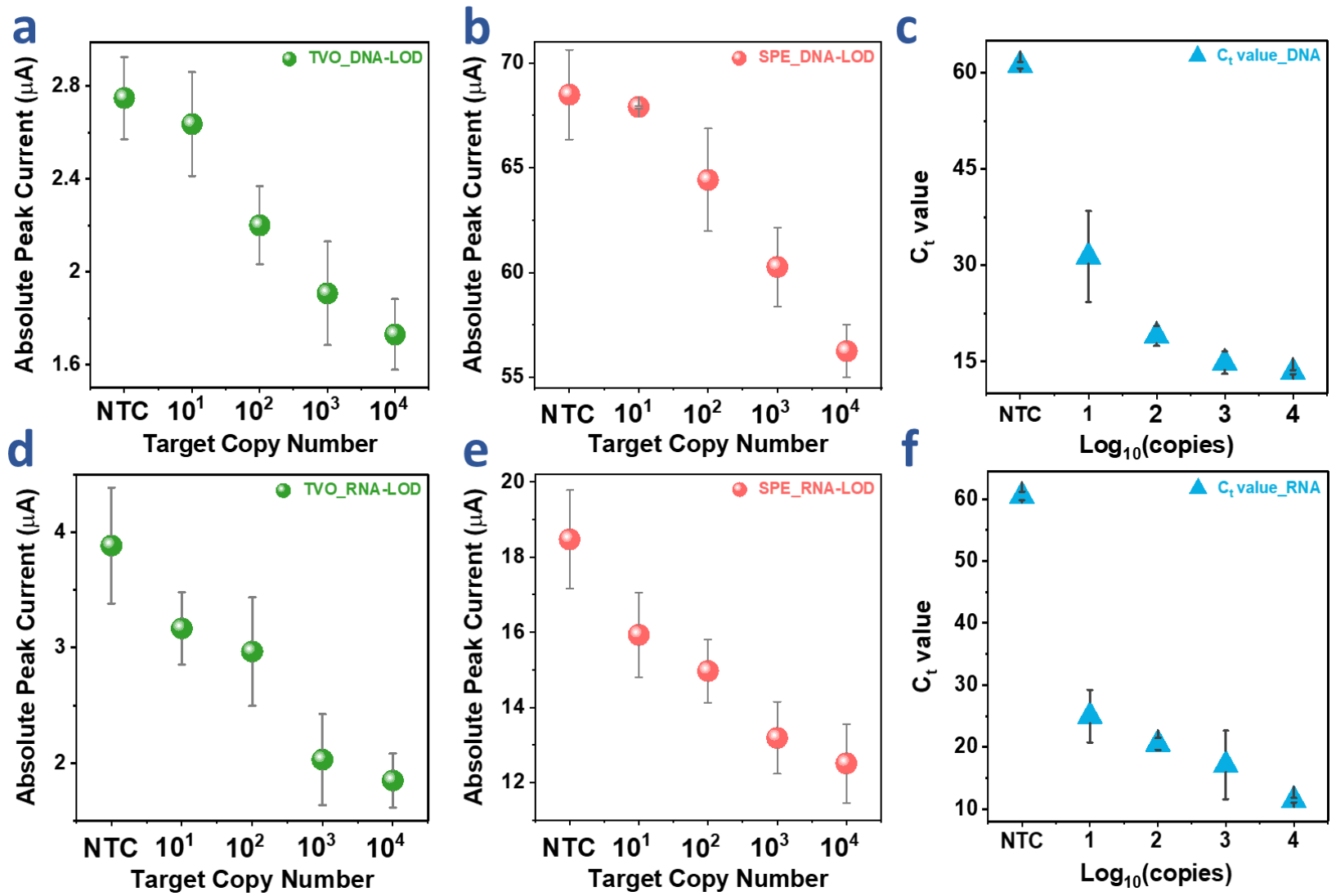

Figure 7 Limit of detection (LOD) study for electrochemical LAMP on pure $10^{1}-10^{4}$ copies of SARS-CoV-2 RdRp plasmid DNA and RNA. $(a, d)$ Tested on 20\%-TVO, (b, e) Tested on SPE, $(c, f)$ real-time fluorescence measurement for LOD using LAMP and RT-LAMP, respectively. Error bars represent standard deviation.

The device sensitivity for the end-point measurement was tested for a range of $10^{1}-10^{4}$ initial target copy number of SARS-CoV-2 RdRp plasmid DNA and in vitro transcribed RNA. It should be noted that the SPE and real-time fluorescence measurement data in this manuscript has been simultaneously but independently obtained with our other manuscript current undergoing peer review (uploaded with this manuscript ${ }^{40}$ ). The sensing response for SWV measurement employing the 20\%TVO electrode was then compared with that of a commercially purchased screen-printed electrode (SPE) and real-time fluorescence (Figure 7). At the same time, the S(I) (\%-change) of the current signal (with respect to NTC) was evaluated for the 20\%-TVO electrode and SPE (SI Table 2). In general, the current response for the TVO electrode was less than that for SPE electrodes for the same concentration of nucleic acid. This could possibly be due to the semiconducting nature of the TVO 
electrode as opposed to conductive carbon electrodes present in SPE. It was also observed that the absolute current decreases with increasing initial target copies while the \%-change increases at the same time. As the amplification efficiency is directly correlated to initial target concentration, increasing initial target copies would increase amplicon concentration that in turn would bind and reduce free $\mathrm{MB}$ in solution, decreasing the electron transfer and resulting current, and in turn increasing S(I) with respect to NTC (SI Table 2). Despite the lesser current signal for the TVO electrode, the S(I) was similar for both TVO and SPE electrodes, indicating comparable performance. The sensing response of 20\%-TVO and SPE was comparable for plasmid DNA and in vitro transcribed SARS-CoV-2 RdRp RNA both (Figure 7 and SI Table 2). We have defined the limit of detection (LOD) as the lowest initial target copies for which the \%-change in the peak height is at least $10 \%$. Therefore, the LOD of $20 \%$-TVO for SARS-CoV-2 RdRp plasmid DNA was $10^{3}$ copies ( 25 copies $/ \mu \mathrm{L}$ ) whereas for in-vitro transcribed RNA was $10^{2}$ copies $(2.5$ copies $/ \mu \mathrm{L})$.

Selectivity and specificity studies using pre-concentration method and comparison with a standard detection technique

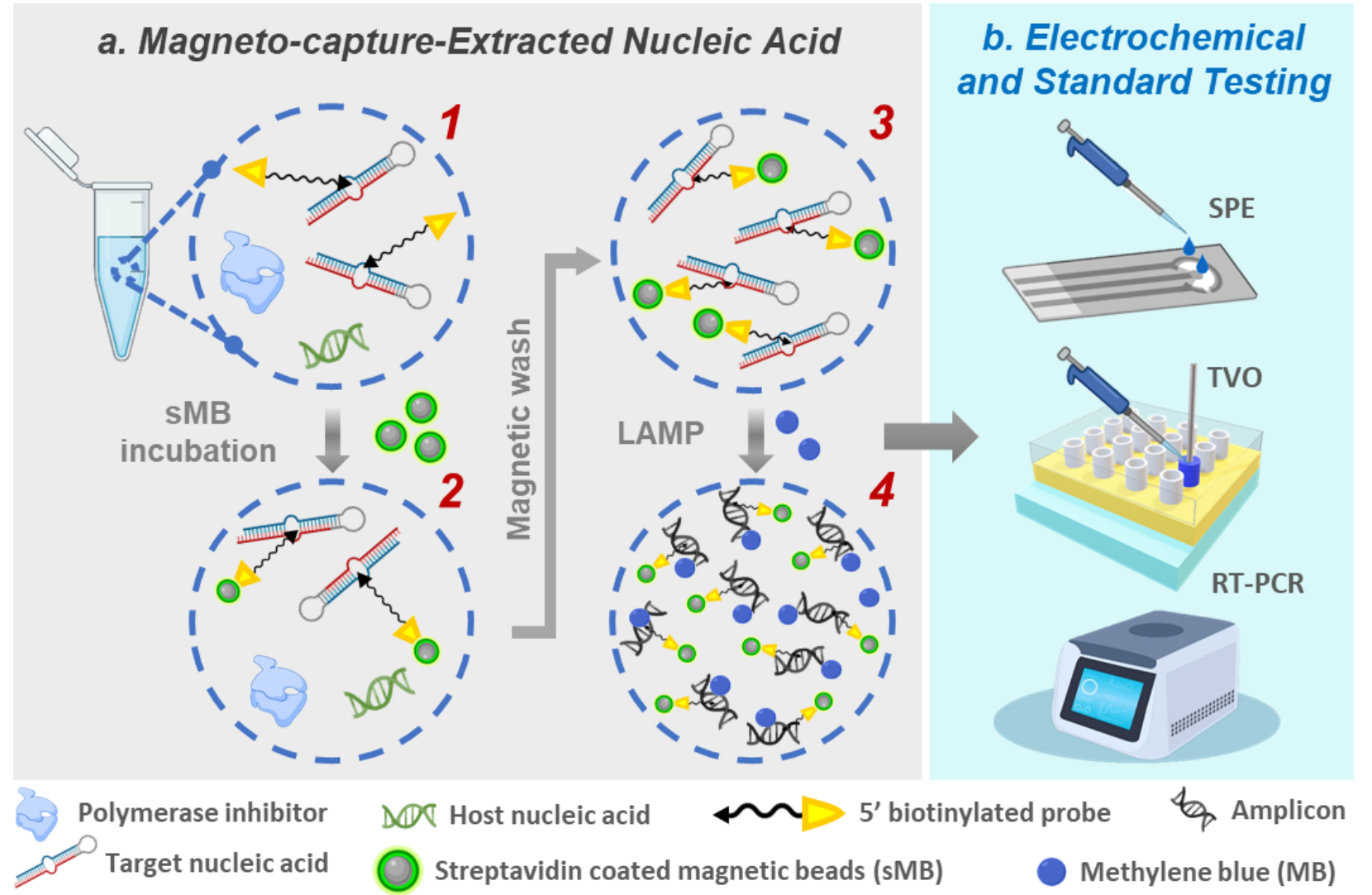

Figure 8 Indirect magnetocapture method. a). Step 1, 5'-biotinylated probe oligonucleotides incubated with a solution containing target nucleic acid as well as host nucleic acid and polymerase inhibitor results in a probe-target complex. Step 2, incubation with 
streptavidin magnetic bead causes immobilization of the probe-target complex on it. Step 3, magnetic decantation wash rids the assay of polymerase inhibitors and host nucleic acid. Step 4, in situ LAMP or in situ RT-LAMP generates amplicon. b). LAMP amplicon detection using electrochemistry or real-time PCR based fluorescence readout depending on the amplification mastermix composition.

Next, we investigated the amenability of our $20 \%$-TVO electrodes with a magneto-extraction mediated pre-concentration of target SARS-CoV-2 nucleic acid. So far our device platform has demonstrated analytical sensitivity of $10^{3}$ and $10^{2}$ copies for plasmid DNA and in-vitro transcribed RNA, respectively, using pure nucleic acid as a template and has comparable performance as that of commercial SPE as well as real-time fluorescence. However, a real-life sample is unlikely to contain pure nucleic acid alone and usually remains present with polymerase inhibitor biomolecules and host nucleic acid, the latter affecting the detection specificity. While traditional real-time PCR NAAT assays circumvent these factors using prior nucleic acid extraction and sequence-specific TaqMan probes, both add to the cost of the experiment. To investigate the applicability of $20 \%$-TVO electrodes in biosensing NAAT of real-life mimicking sample containing polymerase inhibitors and host nucleic acid, the device was used in detecting a sequence-specific magnetic preconcentration of target nucleic acid followed by in situ electrochemical LAMP. A sequence-specific preconcentration of a target nucleic acid could be direct and indirect in nature ${ }^{67}$. In an indirect magnetocapture (Figure 8), the biotinylated probe oligonucleotide anneals to the target nucleic acid which was then immobilized on a streptavidin magnetic bead ${ }^{67}$. A direct magnetocapture, on the other hand, utilizes a bead-immobilized oligonucleotide probe to capture target nucleic acid ${ }^{68}$. In both cases, a magnetic decantation wash would then remove the polymerase inhibitors and host nucleic acid from the solution. In a separate associated manuscript focusing on the magnetocapture aspect of the project (currently undergoing peer review ${ }^{40}$ ), we have demonstrated the superiority of an indirect sequencespecific magnetocapture preconcentration (illustrated in Figure 8) over that of a direct magnetocapture. In combination with an in situ real-time fluorescence LAMP and SPE-based electrochemical in situ LAMP end point readout, it was able to detect 100 and 1000 copies of target SARS-CoV-2 RdRp plasmid DNA. In the current study, the end-point SWV measurements of electrochemical in situ LAMP performed on magneto-extracted SARS-CoV-2 plasmid and RNA were performed on $20 \%$-TVO and SPE to see its compatibility with the 20\%-TVO. The studies (shown in Figure 9b-c and Figure 10b-c) are presented with a simultaneous but independently obtained dataset that is separate from our associated manuscript focusing on the magnetocpature aspect of the project. 

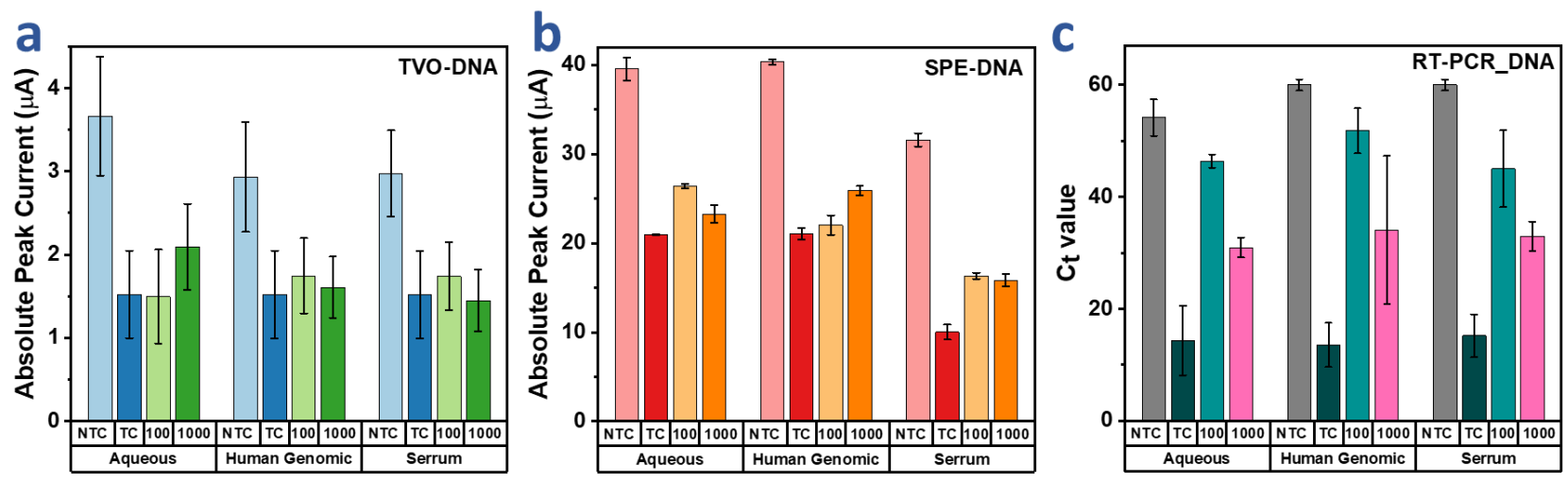

Figure 9 LAMP performed on magneto-extracted SARS-CoV-2 plasmid DNA tested on (a) 20\%-TVO, (b) SPE, respectively. (c) Realtime fluorescence results for the plasmid DNA. The TC sample in each case comprised of $10^{3}$ copies of pure plasmid DNA. Error bars represent standard deviation
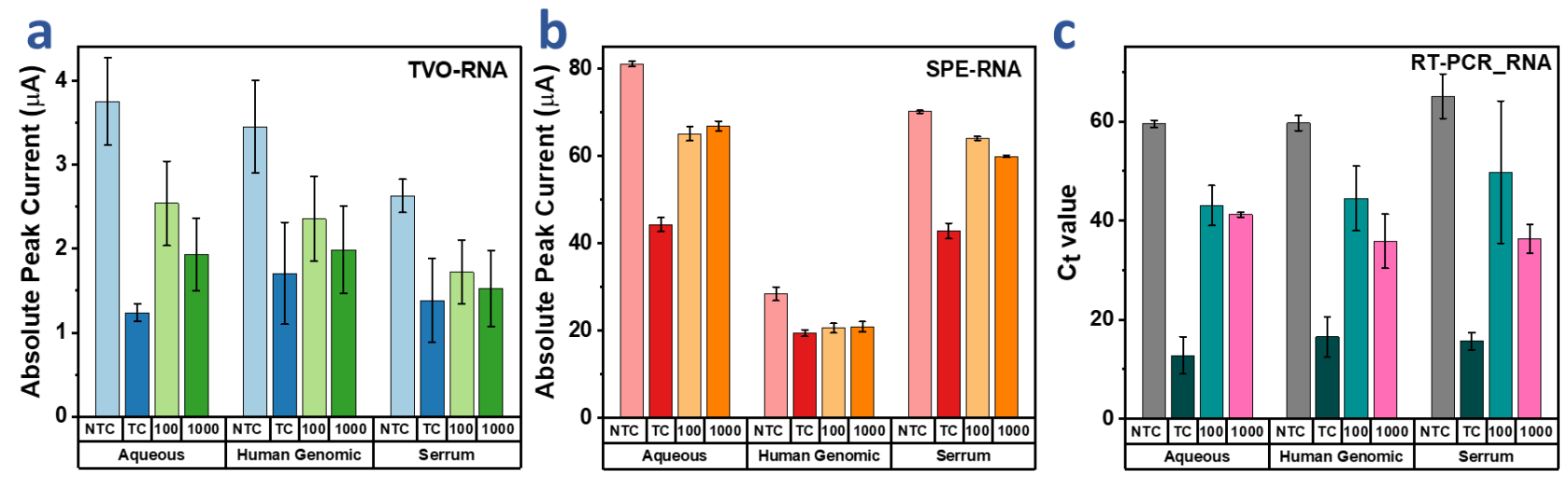

Figure 10 LAMP performed on magneto-extracted SARS-CoV-2 RNA tested on (a) 20\%-TVO, (b) SPE, respectively. (c) Real-time fluorescence results for the plasmid RNA. The TC sample in each case comprised of $10^{3}$ copies of pure RNA. Error bars represent standard deviation.

The grouped column bar graph for the peak current (shown in Figure $9(a-b)$ and Figure $10(a-b)$ ) illustrated that the electrochemical response of magneto-extracted SARS-CoV-2 plasmid and RNA from i) aqueous solution; ii) sample spiked with excess human genomic DNA; and iii) a viral transport medium (VTM)-mimic sample (serum) using 20\%-TVO and SPE, respectively. At the same time, the S(I) percentage change of the current signal, with respect to NTC, corresponding to every variant was evaluated for 20\%-TVO electrode and SPE (SI Table 3). For each variant, two concentrations of $10^{2}$ and $10^{3}$ target copies were tested along with non-magneto-extracted LAMP TC sample with $10^{3}$ copies. As the absence of a template led to the non-existence of amplicon in the NTC samples, the peak current was the highest. Similarly, a significant presence of LAMP amplicon in non-magneto-extracted (i.e., pure) TC samples led to the sequestration of free MB, decreasing the peak current for all cases. The experiments also demonstrated that the current signal, as was in the case of pure nucleic acid-based LAMP assays, was generally lower for 20\%-TVO compared to SPE. 
Ideally, a test sample with more initial target copies was anticipated to produce a higher amplicon and therefore would have a lower value of peak current. Accordingly, NTC should have the highest current followed by $10^{3}$ and $10^{2}$ copies. The peak current, for both SPE and $20 \%$-TVO, while consistently lower than NTC, however, were within the error limit of each other for the magnetocapture detection of $10^{2}$ and $10^{3}$ copies. In addition, the mean current response for magnetoextracted $10^{2}-10^{3}$ copies (Figure 9a-b and 10a-b). This result indicated that the magneto-extraction did not significantly affect the current response (compared to pure nucleic acid templates). While SPE current signal response was consistently higher than that of the $20 \%$-TVO, it was also unable to differentiate between magneto-extracted $10^{2}-10^{3}$ copies. Also, when compared in terms of signal S(I) (SI Table 3) the performance of 20\%-TVO and SPE was equivalent. While having similar analytical sensitivity as that of SPE electrodes, the S(I) for magneto-extracted $10^{2}-10^{3}$ copies were also within error limits of each other. The bi-electrode assembly was thus able to detect pure as well as magneto-extracted 100 to 1000 copies of target SARS-CoV-2 RdRp DNA and RNA, therefore conclusively differentiating a positive from a negative sample. However, the experiments indicated that it will be unable to compute the nucleic acid quantity, at least for low copy numbers, and therefore would unlikely be able to detect the viral load in a potential clinical assay. Interestingly, a similar non-differentiable signal response was present for the SPE electrodes as well as for the fluorescence readout presented in terms of cycle threshold or $C_{t}$ values. This indicated that this probably was not due to inefficient current sensing at the 20\%-TVO electrode and may be an aspect of the magnetocapture assay itself or due to utilization of home-made LAMP mastermix. Overall, the experiments demonstrated that the sensing response of 20\%-TVO and SPE was analogous to each other with LOD in the order of 100 copies $(2.5$ copies/ $\mu \mathrm{L})$ and the presence of human genomic DNA or serum did not hinder the sensing response of TVO.

\section{Conclusion}

In this study, we have built a highly sensitive dual-electrode electrochemical sensor (DEES) coupled with LAMP for the specific detection of SARS-CoV-2. The working electrode of DEES included a transition metal oxide (TMO) sensing layer, which is a rather underexplored class of material for NAAT application. The properties of TMO based sensing layer were modulated by forming a binary metal oxide nanocomposite of titanium dioxide and vanadium oxide $\left(\mathrm{TiO}_{2}: \mathrm{V}_{2} \mathrm{O}_{5}\right)$ with various $\mathrm{Ti}$ content to facilitate sensitive detection. While choosing $\mathrm{TiO}_{2}: \mathrm{V}_{2} \mathrm{O}_{5}$ as the sensing layer, the $\mathrm{MB}$ 
electron transfer performance as a function of sensing layer IEP was also probed. Next, the performance of the electrode was assessed in biosensing and compared against commercially available screen-printed electrodes (SPE) as well as standard real-time fluorescence measurements. The highly sensitive LAMP assay combined with the 20\%-TVO enabled electrochemical approach helped detect pure $10^{1}-10^{4}$ copies of SARS-CoV-2 RdRp plasmid DNA and in-vitro transcribed RNA in an aqueous solution. The DEES analytical sensitivity was in the order of $10^{3}$ copies for plasmid DNA and $10^{2}$ copies for in-vitro transcribed SARS-CoV-2 RdRp RNA and was equivalent to that of the SPE and real-time fluorescence assays performed in real time-PCR instruments.

The device possesses excellent repeatability as suggested by the statistical data set and a low (13.2 to $29.1 \%$ ) coefficient of variation. The implication of DEES suggested excellent selectivity and adoptability when tested for LAMP performed on magneto-extracted SARS-CoV-2 plasmid and RNA with $10^{2}-10^{3}$ copies of target nucleic acid from a) aqueous solution; b) sample spiked with excess human genomic DNA, and c) a viral transport medium (VTM)-mimic sample. The performance of DEES was found to be juxtaposed against that of the standard real-time fluorescence and SPEs. These experiments demonstrated that DEES, a novel class of device, by itself or in combination with a preconcentration technique, was capable of efficacious detection of low copies of target nucleic acid in pure form as well as from a real-life mimic sample. Such performance and selectivity would be critical for future studies to be conducted on clinical samples. 


\section{Supporting information}

Supporting information contains crystallite size and film thickness values, signal \%-change for electrochemical detection, electroanalytical data of $100 \mu \mathrm{M}$ MB for FTO alone and 20\%-TVO deposited FTO, redox pair for the electrochemical probe methylene blue (MB), additional X-ray diffraction patterns, X-ray photoelectron spectroscopy analysis, and FE-SEM micrographs. Measured thickness profiles, Bode plot, chronoamperometry measurements, I-V characteristics of $20 \%$-TVO collected for $100 \mu \mathrm{M} \mathrm{MB}$ and buffer alone, current signal comparison of $20 \%$-TVO electrode and $\mathrm{MnO}_{2}$ electrode, and chronoamperometry of NTC and plasmid DNA LAMP.

\section{Author Contribution}

TA, ST, SG, and AK have conceptualized the experiments. TA designed the electrodes, characterized them, and performed the electrochemical analysis. ST has conducted the magnetocapture and optimized the LAMP experiments. MS guided plasmid procurement, microbiology, cell culture, and in vitro transcription.TA, ST, SG, and AK wrote the manuscript. All authors edited and approved the final manuscript.

\section{Conflict of Interest}

The team has applied for two Indian patents (filing number: 202111028722 and 202111037358) on the work described in this study.

\section{Acknowledgment}

This work was supported by the Bennett University Ph.D. fellowship to Tanvi Agarkar and Sayantan Tripathy, Bennett University Seed Grant funding to Dr Ashvani Kumar, Department of Science and Technology (DST) Nanomission grant (No: DST/NM/NB/2018/189) and Department of Biotechnology- Biotechnology Industry Research Assistance Council (BIRAC) grant (No: BT/PR40297/COD/139/6/2020). 


\section{References}

(1) Vezza, V. J.; Butterworth, A.; Lasserre, P.; Blair, E. O.; MacDonald, A.; Hannah, S.; Rinaldi, C.; Hoskisson, P. A.; Ward, A. C.; Longmuir, A.; Setford, S.; Farmer, E. C. W.; Murphy, M. E.; Corrigan, D. K. An Electrochemical SARS-CoV-2 Biosensor Inspired by Glucose Test Strip Manufacturing Processes. Chem. Commun. 2021, 57 (30), 3704-3707. https://doi.org/10.1039/d1cc00936b.

(2) WHO Coronavirus (COVID-19) Dashboard I WHO Coronavirus (COVID-19) Dashboard With Vaccination Data https://covid19.who.int/ (accessed Nov 23, 2021).

(3) Lan, L.; Xu, D.; Ye, G.; Xia, C.; Wang, S.; Li, Y.; Xu, H. Positive RT-PCR Test Results in Patients Recovered from COVID-19. JAMA - J. Am. Med. Assoc. 2020, 323 (15), 1502-1503. https://doi.org/10.1001/jama.2020.2783.

(4) Chaibun, T.; Puenpa, J.; Ngamdee, T.; Boonapatcharoen, N.; Athamanolap, P.; O’Mullane, A. P.; Vongpunsawad, S.; Poovorawan, Y.; Lee, S. Y.; Lertanantawong, B. Rapid Electrochemical Detection of Coronavirus SARS-CoV-2. Nat. Commun. 2021, 12 (1), 1-10. https://doi.org/10.1038/s41467-021-21121-7.

(5) de Lima, L. F.; Ferreira, A. L.; Torres, M. D. T.; de Araujo, W. R.; de la Fuente-Nunez, C. Minute-Scale Detection of SARS-CoV-2 Using a Low-Cost Biosensor Composed of Pencil Graphite Electrodes. Proc. Natl. Acad. Sci. U. S. A. 2021, 118 (30), 1-9. https://doi.org/10.1073/pnas.2106724118.

(6) Vadlamani, B. S.; Uppal, T.; Verma, S. C.; Misra, M. Functionalized Tio2 Nanotube-Based Electrochemical Biosensor for Rapid Detection of Sars-Cov-2. Sensors (Switzerland) 2020, 20 (20), 5871-5881. https://doi.org/10.3390/s20205871.

(7) Eun, H.; Schuck, A.; Hi, S.; Lee, Y.; Kang, M.; Kim, Y. Sensitive Electrochemical Biosensor Combined with Isothermal Amplification for Point-of-Care COVID-19 Tests. Biosens. Bioelectron. J. 2021, 182 (January). 
(8) Piepenburg, O.; Williams, C. H.; Stemple, D. L.; Armes, N. A. DNA Detection Using Recombination Proteins. PLoS Biol. 2006, 4 (7), 1115-1121. https://doi.org/10.1371/journal.pbio.0040204.

(9) Gu, L.; Yan, W.; Liu, L.; Wang, S.; Zhang, X.; Lyu, M. Research Progress on Rolling Circle Amplification (Rca)-Based Biomedical Sensing. Pharmaceuticals 2018, 11 (2), 1-19. https://doi.org/10.3390/ph11020035.

(10) Alexandra Martin, Laurent Bouffier, Kathryn B. Grant, B. L. and D. M. Real-Time Electrochemical LAMP: A Rational Comparative Study of Different DNA Intercalating and Non-Intercalating Redox Probes. Analyst 2016, 141 (13), 4196-4203. https://doi.org/10.1039/C6AN00867D.

(11) Ahmed, M. U.; Nahar, S.; Safavieh, M.; Zourob, M. Real-Time Electrochemical Detection of Pathogen DNA Using Electrostatic Interaction of a Redox Probe. Analyst 2013, 138 (3), 907915. https://doi.org/10.1039/c2an36153a.

(12) Yee, E. H.; Sikes, H. D. Polymerization-Based Amplification for Target-Specific Colorimetric Detection of Amplified Mycobacterium Tuberculosis DNA on Cellulose. ACS sensors 2020, 5 (2), 308-312. https://doi.org/10.1021/acssensors.9b02424.

(13) Yan, L.; Zhou, J.; Zheng, Y.; Gamson, A. S.; Roembke, B. T.; Nakayama, S.; Sintim, H. O. Isothermal Amplified Detection of DNA and RNA. Mol. Biosyst. 2014, 10 (5), 970-1003. https://doi.org/10.1039/c3mb70304e.

(14) Crippa, M.; Bartolucci, G. B.; Toffoletto, F.; Marcer, G. Loop-Mediated Isothermal Amplification of DNA Tsugunori. Med. del Lav. 2012, 103 (3), 187-197.

(15) González-González, E.; Lara-Mayorga, I. M.; Rodríguez-Sánchez, I. P.; Zhang, Y. S.; MartínezChapa, S. O.; Santiago, G. T. De; Alvarez, M. M. Colorimetric Loop-Mediated Isothermal Amplification (LAMP) for Cost-Effective and Quantitative Detection of SARS-CoV-2: The Change in Color in LAMP-Based Assays Quantitatively Correlates with Viral Copy Number. Anal. Methods 2021, 13 (2), 169-178. https://doi.org/10.1039/D0AY01658F. 
(16) Mori, Y.; Kitao, M.; Tomita, N.; Notomi, T. Real-Time Turbidimetry of LAMP Reaction for Quantifying Template DNA. J. Biochem. Biophys. Methods 2004, 59 (2), 145-157. https://doi.org/10.1016/j.jbbm.2003.12.005.

(17) Yang, K. L. A.; Wu, S. Y.; Kwok, H. C.; Ho, H. P.; Kong, S. K. Using Loop-Mediated Isothermal DNA Amplification (LAMP) and Spectral Surface Plasmon Resonance (SPR) to Detect Methicillin-Resistance S. Aureus (MRSA). Proc. - 2012 Int. Conf. Biomed. Eng. Biotechnol. iCBEB 2012 2012, 4, 647-650. https://doi.org/10.1109/iCBEB.2012.462.

(18) Fabiani, L.; Saroglia, M.; Galatà, G.; De Santis, R.; Fillo, S.; Luca, V.; Faggioni, G.; D’Amore, N.; Regalbuto, E.; Salvatori, P.; Terova, G.; Moscone, D.; Lista, F.; Arduini, F. Magnetic Beads Combined with Carbon Black-Based Screen-Printed Electrodes for COVID-19: A Reliable Aand Miniaturized Electrochemical Immunosensor for SARS-CoV-2 Detection in Saliva. Biosens. Bioelectron. 2021, 171, 112686. https://doi.org/10.1016/j.bios.2020.112686.

(19) Cesewski, E.; Johnson, B. N. Electrochemical Biosensors for Pathogen Detection. Biosens. Bioelectron. 2020, 159 (April), 112214. https://doi.org/10.1016/j.bios.2020.112214.

(20) Rasheed, P. A.; Sandhyarani, N. Electrochemical DNA Sensors Based on the Use of Gold Nanoparticles: A Review on Recent Developments. Microchim. Acta 2017, 184 (4), 9811000. https://doi.org/10.1007/s00604-017-2143-1.

(21) Hsieh, K.; Patterson, A. S.; Ferguson, B. S.; Plaxco, K. W.; Soh, H. T. Rapid, Sensitive, and Quantitative Detection of Pathogenic DNA at the Point of Care through Microfluidic Electrochemical Quantitative Loop-Mediated Isothermal Amplification. Angew. Chemie Int. Ed. 2012, 51 (20), 4896-4900. https://doi.org/10.1002/anie.201109115.

(22) Murphy, J. N.; Cheng, A. K. H.; Yu, H. Z.; Bizzotto, D. On the Nature of DNA Self-Assembled Monolayers on Au: Measuring Surface Heterogeneity with Electrochemical in Situ Fluorescence Microscopy. J. Am. Chem. Soc. 2009, 131 (11), 4042-4050. https://doi.org/10.1021/ja808696p.

(23) Mahari, S.; Roberts, A.; Shahdeo, D.; Gandhi, S. ECovSens-Ultrasensitive Novel In-House 
Built Printed Circuit Board Based Electrochemical Device for Rapid Detection of NCovid-19. bioRxiv 2020, No. April. https://doi.org/10.1101/2020.04.24.059204.

(24) Rotariu, L.; Istrate, O. M.; Bala, C. Poly(Allylamine Hydrochloride) Modified Screen-Printed Carbon Electrode for Sensitive and Selective Detection of NADH. Sensors Actuators, $B$ Chem. 2014, 191, 491-497. https://doi.org/10.1016/j.snb.2013.09.077.

(25) Istrate, O. M.; Rotariu, L.; Marinescu, V. E.; Bala, C. NADH Sensing Platform Based on Electrochemically Generated Reduced Graphene Oxide-Gold Nanoparticles Composite Stabilized with Poly(Allylamine Hydrochloride). Sensors Actuators, B Chem. 2016, 223, 697704. https://doi.org/10.1016/j.snb.2015.09.142.

(26) Zhu, Q.; Liang, B.; Pei, Y.; Ye, X.; Liang, X. Study of Fabrication Conditions of ATP Biosensor Based on Screen-Printed Electrode. Proc. IEEE Sensors 2016, 1-3. https://doi.org/10.1109/ICSENS.2016.7808858.

(27) Nagatani, N.; Yamanaka, K.; Saito, M.; Koketsu, R.; Sasaki, T.; Ikuta, K.; Miyahara, T.; Tamiya, E. Semi-Real Time Electrochemical Monitoring for Influenza Virus RNA by Reverse Transcription Loop-Mediated Isothermal Amplification Using a USB Powered Portable Potentiostat. Analyst 2011, 136 (24), 5143-5150. https://doi.org/10.1039/c1an15638a.

(28) Zhou, Y.; Ni, X.; Ren, Z.; Ma, J.; Xu, J.; Chen, X. A Flower-like NiO-SnO2 Nanocomposite and Its Non-Enzymatic Catalysis of Glucose. RSC Adv. 2017, 7 (71), 45177-45184. https://doi.org/10.1039/c7ra07582k.

(29) Taghizadeh, M. T.; Vatanparast, M. Preparation and Evaluation of Nafion/SnO2 Nanocomposite for Improving the Chemical Durability of Proton Exchange Membranes in Fuel Cells. RSC Adv. 2016, 6 (62), 56819-56826. https://doi.org/10.1039/c6ra07849d.

(30) Liu, Y.; Jiao, Y.; Yin, B.; Zhang, S.; Qu, F.; Wu, X. Enhanced Electrochemical Performance of Hybrid SnO2@MOx (M = Ni, Co, Mn) Core-Shell Nanostructures Grown on Flexible Carbon Fibers as the Supercapacitor Electrode Materials. J. Mater. Chem. A 2015, 3 (7), 3676-3682. https://doi.org/10.1039/c4ta06339b. 
(31) Bhardwaj, A.; Kim, I. ho; Hong, J. woon; Kumar, A.; Song, S. J. Transition Metal Oxide (Ni, Co, Fe)-Tin Oxide Nanocomposite Sensing Electrodes for a Mixed-Potential Based NO2 Sensor. Sensors Actuators, B Chem. 2019, 284 (2), 534-544.

https://doi.org/10.1016/j.snb.2019.01.003.

(32) Cai, H.; Sun, R.; Yang, X.; Liang, X.; Wang, C.; Sun, P.; Liu, F.; Zhao, C.; Sun, Y.; Lu, G. MixedPotential Type NOx Sensor Using Stabilized Zirconia and MoO3-In2O3 Nanocomposites. Ceram. Int. 2016, 42 (10), 12503-12507. https://doi.org/10.1016/j.ceramint.2016.03.243.

(33) Chin, S. F.; Lim, L. S.; Pang, S. C.; Sum, M. S. H.; Perera, D. Carbon Nanoparticle Modified Screen Printed Carbon Electrode as a Disposable Electrochemical Immunosensor Strip for the Detection of Japanese Encephalitis Virus. Microchim. Acta 2017, 184 (2), 491-497. https://doi.org/10.1007/s00604-016-2029-7.

(34) Khoo, E.; Wang, J.; Ma, J.; Lee, P. S. Electrochemical Energy Storage in a $\beta-N a 0.33 V 205$ Nanobelt Network and Its Application for Supercapacitors. J. Mater. Chem. 2010, 20 (38), 8368-8374. https://doi.org/10.1039/c0jm00652a.

(35) Agarkar, T.; Nair, V. K.; Tripathy, S.; Chawla, V.; Ghosh, S.; Kumar, A. Oxygen Vacancy Modulated MnO2 Bi-Electrode System for Attomole-Level Pathogen Nucleic Acid Sequence Detection. Electrochim. Acta 2022, 139876. https://doi.org/10.1016/J.ELECTACTA.2022.139876.

(36) Inzelt, G. Pseudo-Reference Electrodes. In Handbook of Reference Electrodes; Springer, Berlin, Heidelberg, 2013; pp 331-332. https://doi.org/10.1007/978-3-642-36188-3_14.

(37) Solanki, P. R.; Kaushik, A.; Agrawal, V. V.; Malhotra, B. D. Nanostructured Metal OxideBased Biosensors. NPG Asia Mater. 2011, 3 (1), 17-24. https://doi.org/10.1038/asiamat.2010.137.

(38) Rashid, M. A.; Mondal, B. K.; Rubel, M. H. K.; Rahman, M. M.; Mefford, O. T.; Hossain, J. Synthesis of Self-Assembled Randomly Oriented VO2nanowires on a Glass Substrate by a Spin Coating Method. Inorg. Chem. 2020, 59 (21), 15707-15716. 
https://doi.org/10.1021/acs.inorgchem.0c02108.

(39) Pandeeswari, R.; Karn, R. K.; Jeyaprakash, B. G. Ethanol Sensing Behaviour of Sol-Gel DipCoated TiO2 Thin Films. Sensors Actuators, B Chem. 2014, 194, 470-477. https://doi.org/10.1016/j.snb.2013.12.122.

(40) Tripathy, S.; Agarkar, T.; Talukdar, A.; Sengupta, M.; Kumar, A.; Ghosh, S. A Comparative Evaluation of Indirect Sequence-Specific Magnetoextraction-Aided Fluorescence and Electrochemical LAMP with SARS-CoV-2 Nucleic Acid as the Analyte. 2022. https://doi.org/10.26434/chemrxiv-2022-x2qxq.

(41) Jang, W. S.; Lim, D. H.; Yoon, J.; Kim, A.; Lim, M.; Nam, J.; Yanagihara, R.; Ryu, S. W.; Jung, B. K.; Ryoo, N. H.; Lim, C. S. Development of a Multiplex Loop-Mediated Isothermal Amplification (LAMP) Assay for on-Site Diagnosis of SARS CoV-2. PLoS One 2021, 16 (3), e0248042. https://doi.org/10.1371/JOURNAL.PONE.0248042.

(42) Eugene, K. Nanostructured Transition Metal Oxide (TMO) for Electrochemical Devices, Nanyang Technological University, Singapore., 2011. https://doi.org/https://doi.org/10.32657/10356/50523.

(43) González, G.; Saraiva, S. M.; Aliaga, W. Isoelectric Points for Niobium and Vanadium Pentoxides. J. Dispers. Sci. Technol. 1994, 15 (2), 249. https://doi.org/10.1080/01932699408943555.

(44) Harvey, D. Overview of Electrochemistry https://chem.libretexts.org/Bookshelves/Analytical_Chemistry/Book\%3A_Analytical_Chemi stry_2.1_(Harvey)/11\%3A_Electrochemical_Methods/11.01\%3A_Overview_of_Electrochem istry.

(45) Electrical Double Layer and Charging Current.

(46) Couturier, G.; Salardenne, J.; Sribi, C.; Rosso, M. Electronic and Ionic Conductivity Measurements in Ionic Conductors with a High Band Gap. Solid State Ionics 1983, 9-10 
(PART 1), 699-705. https://doi.org/10.1016/0167-2738(83)90317-X.

(47) Raval, D.; Jani, M.; Chaliyawala, H.; Joshi, A.; Mukhopadhyay, I.; Ray, A. Solar to Chemical Energy Conversion Using Titania Nanorod Photoanodes Augmented by Size Distribution of Plasmonic Au-Nanoparticle. Mater. Chem. Phys. 2019, 231 (April), 322-334. https://doi.org/10.1016/j.matchemphys.2019.04.025.

(48) Subba Reddy, C. V.; Park, K. II; Mho, S. II; Yeo, I. H.; Park, S. M. Simple Preparation of V2O5 Nanostructures and Their Characterization. Bull. Korean Chem. Soc. 2008, 29 (10), 20612064. https://doi.org/10.5012/bkcs.2008.29.10.2061.

(49) Zhou, W.; Liu, Q.; Zhu, Z.; Zhang, J. Preparation and Properties of Vanadium-Doped TiO2 Photocatalysts. J. Phys. D. Appl. Phys. 2010, 43 (3). https://doi.org/10.1088/0022$3727 / 43 / 3 / 035301$.

(50) Wang, Y.; Li, L.; Huang, X.; Li, Q.; Li, G. New Insights into Fluorinated TiO2 (Brookite, Anatase and Rutile) Nanoparticles as Efficient Photocatalytic Redox Catalysts. RSC Adv. 2015, 5 (43), 34302-34313. https://doi.org/10.1039/c4ra17076h.

(51) Taha, M.; Walia, S.; Ahmed, T.; Headland, D.; Withayachumnankul, W.; Sriram, S.; Bhaskaran, M. Insulator-Metal Transition in Substrate-Independent VO2 Thin Film for Phase-Change Devices. Sci. Rep. 2017, 7 (1), 1-10. https://doi.org/10.1038/s41598-01717937-3.

(52) Lu, Y.; Liu, L.; Mandler, D.; Lee, P. S. High Switching Speed and Coloration Efficiency of Titanium-Doped Vanadium Oxide Thin Film Electrochromic Devices. J. Mater. Chem. C 2013, 1 (44), 7380-7386. https://doi.org/10.1039/c3tc31508h.

(53) Dong, Y.; Niu, X.; Song, W.; Wang, D.; Chen, L.; Yuan, F.; Zhu, Y. Facile Synthesis of Vanadium Oxide/Reduced Graphene Oxide Composite Catalysts for Enhanced Hydroxylation of Benzene to Phenol. Catalysts 2016, 6 (5). https://doi.org/10.3390/catal6050074. 
(54) Bharti, B.; Kumar, S.; Lee, H. N.; Kumar, R. Formation of Oxygen Vacancies and Ti3+ State in TiO2 Thin Film and Enhanced Optical Properties by Air Plasma Treatment. Sci. Rep. 2016, 6 (August), 1-12. https://doi.org/10.1038/srep32355.

(55) ZHAO, X.; YANG, Q.; CUI, J. XPS Study of Surface Absorbed Oxygen of ABO3 Mixed Oxides. J. Rare Earths 2008, 26 (4), 511-514. https://doi.org/10.1016/S1002-0721(08)60128-3.

(56) Ciftyürek, E.; Šmíd, B.; Li, Z.; Matolín, V.; Schierbaum, K. Spectroscopic Understanding of Sno2 and Wo3 Metal Oxide Surfaces with Advanced Synchrotron Based; XPS-UPS and near Ambient Pressure (NAP) XPS Surface Sensitive Techniques for Gas Sensor Applications under Operational Conditions. Sensors (Switzerland) 2019, 19 (21). https://doi.org/10.3390/s19214737.

(57) Yamaguchi, Y.; Nagasawa, Y.; Shimomura, S.; Tabata, K.; Suzuki, E. A Density Functional Theory Study of the Interaction of Oxygen with a Reduced SnO2 (110) Surface. Chem. Phys. Lett. 2000, 316 (5-6), 477-482. https://doi.org/10.1016/S0009-2614(99)01365-2.

(58) Wang, L.; Qi, T.; Wang, J.; Zhang, S.; Xiao, H.; Ma, Y. Uniform Dispersion of Cobalt Nanoparticles over Nonporous TiO2 with Low Activation Energy for Magnesium Sulfate Recovery in a Novel Magnesia-Based Desulfurization Process. J. Hazard. Mater. 2018, 342, 579-588. https://doi.org/10.1016/j.jhazmat.2017.08.080.

(59) Wang, J. T.; Shi, X. L.; Liu, W. W.; Zhong, X. H.; Wang, J. N.; Pyrah, L.; Sanderson, K. D.; Ramsey, P. M.; Hirata, M.; Tsuri, K. Influence of Preferred Orientation on the Electrical Conductivity of Fluorine-Doped Tin Oxide Films. Sci. Rep. 2015, 4, 1-9. https://doi.org/10.1038/srep03679.

(60) Torrisi, V.; Censabella, M.; Piccitto, G.; Compagnini, G.; Grimaldi, M. G.; Ruffino, F. Characteristics of Pd and Pt Nanoparticles Produced by Nanosecond Laser Irradiations of Thin Films Deposited on Topographically-Structured Transparent Conductive Oxides. Coatings 2019, 9 (2). https://doi.org/10.3390/COATINGS9020068.

(61) Macdonald, M. A.; Andreas, H. A. Method for Equivalent Circuit Determination for 
Electrochemical Impedance Spectroscopy Data of Protein Adsorption on Solid Surfaces. Electrochim. Acta 2014, 129, 290-299. https://doi.org/10.1016/j.electacta.2014.02.046.

(62) Lai, Y.; Li, Y.; Jiang, L.; Xu, W.; Lv, X.; Li, J.; Liu, Y. Electrochemical Behaviors of Co-Deposited $\mathrm{Pb} / \mathrm{Pb}-\mathrm{MnO} 2$ Composite Anode in Sulfuric Acid Solution - Tafel and EIS Investigations. J. Electroanal. Chem. 2012, 671, 16-23. https://doi.org/10.1016/j.jelechem.2012.02.011.

(63) Faulkner, A. J. B. L. R. ELECTROCHEMICAL METHODS Fundamentals and Applications; 2001; Vol. 2. https://doi.org/10.1016/B978-0-12-381373-2.00056-9.

(64) Tsaloglou, M. N.; Nemiroski, A.; Camci-Unal, G.; Christodouleas, D. C.; Murray, L. P.; Connelly, J. T.; Whitesides, G. M. Original Format: Handheld Isothermal Amplification and Electrochemical Detection of DNA in Resource-Limited Settings. Anal. Biochem. 2018, 543 (December 2017), 116-121. https://doi.org/10.1016/j.ab.2017.11.025.

(65) Rohs, R.; Sklenar, H. Methylene Blue Binding to DNA with Alternating GC Base Sequence: Continuum Treatment of Salt Effects. Indian J. Biochem. Biophys. 2001, 38 (1-2), 1-6.

(66) Vardevanyan, P. O.; Antonyan, A. P.; Parsadanyan, M. A.; Shahinyan, M. A.; Hambardzumyan, L. A. Mechanisms for Binding between Methylene Blue and DNA. J. Appl. Spectrosc. 2013, 80 (4), 595-599. https://doi.org/10.1007/s10812-013-9811-7.

(67) Tsai, S. P.; Wong, A.; Mai, E.; Chan, P.; Mausisa, G.; Vasser, M.; Jhurani, P.; Jakobsen, M. H.; Wong, W. L. T.; Stephan, J. P. Nucleic Acid Capture Assay, a New Method for Direct Quantitation of Nucleic Acids. Nucleic Acids Res. 2003, 31 (6), e25. https://doi.org/10.1093/nar/gng025.

(68) Pezzi, H. M.; Niles, D. J.; Schehr, J. L.; Beebe, D. J.; Lang, J. M. Integration of Magnetic BeadBased Cell Selection into Complex Isolations. ACS Omega 2018, 3 (4), 3908-3917. https://doi.org/10.1021/ACSOMEGA.7B01427/SUPPL_FILE/A07B01427_SI_001.PDF. 